Article

\title{
A Forecasting Method for Macro-Control Policy of Heating Energy Consumption and Carbon Emissions Based on Building Area and Energy Intensity: A Case Study of Northern China
}

\author{
Yu Zheng ${ }^{1, *}$, Wenlong Yin ${ }^{2}$, Wenjie Zhang ${ }^{2}{ }^{\circledR}$, Jinhan Liang ${ }^{3}$, Kangyong Liu ${ }^{2}$ and Kuan Wang ${ }^{4}$ \\ 1 School of Mechanical, Electronic and Control Engineering, Beijing Jiaotong University, Beijing 100044, China \\ 2 School of Energy and Power Engineering, Nanjing University of Science and Technology, \\ Nanjing 210094, China; 13251611050@163.com (W.Y.); zhangwenjie001@139.com (W.Z.); \\ conan1016@live.com (K.L.) \\ 3 Norendar Internation Ltd., Shijiazhaung 050030, China; liang289922@126.com \\ 4 China Railway Construction Group Co., Ltd., Beijing 100043, China; wangkuan@ztjs.cn \\ * Correspondence: 19116054@bjtu.edu.cn
}

Citation: Zheng, Y.; Yin, W.; Zhang, W.; Liang, J.; Liu, K.; Wang, K. A

\section{Forecasting Method for}

Macro-Control Policy of Heating Energy Consumption and Carbon Emissions Based on Building Area and Energy Intensity: A Case Study of Northern China. Energies 2022, 15, 1153. https://doi.org/10.3390/ en15031153

Academic Editors: Shi-Jie Cao, Wei Feng and Vincenzo Costanzo

Received: 29 December 2021

Accepted: 2 February 2022

Published: 4 February 2022

Publisher's Note: MDPI stays neutral with regard to jurisdictional claims in published maps and institutional affiliations.

Copyright: () 2022 by the authors Licensee MDPI, Basel, Switzerland. This article is an open access article distributed under the terms and conditions of the Creative Commons Attribution (CC BY) license (https:/ / creativecommons.org/licenses/by/ $4.0 /)$.

\begin{abstract}
In response to extreme climate change, China has set a goal of reaching emission peak by 2030 and achieving carbon neutrality by 2050. Energy conservation and emission reduction of building heating in northern China are key to achieving this goal. Based on building area prediction and energy consumption intensity, this paper establishes a model for calculating heating energy consumption and carbon emissions in northern residential buildings at the macro level, which provides a basis for formulating policies related to heating and emission reduction in northern buildings. Based on the research method of scenario projection, combining the carbon emission subsets and future heating energy mix projections in northern China, the heating energy consumption in northern China decreases to 175, 149 and 135 Mtce in 2050 under the baseline, medium control and strict control scenarios, respectively. The heating energy consumption in the northern region should be controlled at least under the medium control scheme. Under this scenario, building heating carbon emissions in the north could be reduced to $450 \mathrm{MtCO}_{2}$ by 2050, or $280 \mathrm{MtCO}_{2}$ if more stringent abatement technologies are adopted. In order to achieve this goal, a combination of energy-saving technologies must be used. The use of biomass and solar technologies should be emphasized in rural heating, while envelope renovation makes the greatest contribution to heating energy savings, with envelope renovation contributing up to 92 Mtce to urban heating.
\end{abstract}

Keywords: heating; northern China; energy saving; carbon emission; model forecasting

\section{Introduction}

In response to extreme climate change, in 2018 the Intergovernmental Panel on Climate Change released a report showing that the world must limit global warming to $1.5^{\circ} \mathrm{C}$ [1]. Countries can only achieve this goal if they achieve zero carbon emissions by the midcentury. To this end, China announced at the 75th session of the United Nations General Assembly that it would take stronger policy measures to peak $\mathrm{CO}_{2}$ emissions by 2030 and achieve carbon neutrality by 2060 [2].

The 2030 and 2060 carbon emission targets provide a concrete timeline for the transformation of China's energy mix. In view of the current situation in China, China's energy reform and building energy efficiency work must start from the national situation and find a way to meet its own characteristics. The northern region of China is located to the north of the Qinling-Huaihe line, covering two climatic regions of severe cold and cold regions. Due to the low temperature in winter, the heating in northern towns is mainly concentrated heating. Fifteen provinces and municipalities with a large coverage rate of central heating in northern China are Beijing, Tianjin, Hebei, Shanxi, Inner Mongolia, Heilongjiang, Jilin, 
Liaoning, Shandong, Henan, Shaanxi, Gansu, Qinghai, Ningxia and Xinjiang. In the northern part of China, due to the winter heating demand, the adjustment of its heating energy use structure and carbon emission reduction is the key to achieving the national carbon emission target. The statistics and prediction of heating energy consumption and the carbon emission data of northern buildings are important for a comprehensive understanding of the current situation of building energy consumption in northern China, discovering the problematic aspects of building energy use, controlling building carbon emissions and guiding the development of building energy conservation work, and the research results can provide strong data support for this.

The current domestic and international energy consumption calculation methods can be divided into two categories: one is the building energy consumption obtained by statistical analysis using survey data, and the other is the building energy consumption obtained by using calculation models based on macroscopic data [3]. Microscopic data statistics usually adopt the method of sampling survey to conduct statistics on various energy consumption data of various buildings, and the United States, Japan, Denmark and other developed countries have set up special building energy consumption statistics institutions to investigate building energy consumption. The U.S. Energy Information Administration (EIA) divides buildings into two categories, residential buildings and commercial buildings, and conducts surveys and statistics every four years, and then processes the data through regression analysis, engineering models and adjusted estimates to decompose energy consumption into different energy-using terminals [4]. The U.S. housing metering energy model uses the National Energy Modeling System (NEMS) to analyze and calculate building energy [5]. The model includes both a top-down macroeconomic model and a bottom-up energy supply and demand model.

The econometric model LEAP [6], jointly developed by the Stockholm Environment Association and Boston University, USA, can be used as a scenario-based energy-environment modeling tool for energy demand analysis and its corresponding environmental impact analysis and cost-benefit analysis. Based on the LEAP model, Liu, J.L. et al. [7] developed a building sector energy system model (PECE-Building) by setting three scenariosbaseline scenario (BAU), autonomous contribution scenario (NDC) and enhanced low carbon (ELC) - and analyzed the energy demand and $\mathrm{CO}_{2}$ emission trends of the building sector under different development paths from 2013 to 2050, concluding that heating is the most important area of emission reduction in northern cities and towns. Li Xinyi [8] from Chongqing University used cluster analysis and statistical data-based definitions to select residential building prototypes to construct community- and city-scale residential building area energy consumption models around community-scale and urban-scale residential buildings, while using machine learning methods to construct a residential building energy demand prediction tool that took into account the behavioral characteristics of people and future meteorological corrections. Xueling Liu et al. [9] considered climate and population changes, proposed an evaluation method for per capita energy consumption per unit area and simulated and calculated the cooling and heating energy consumption of various types of buildings in the Tianjin area for the next 30 years according to the different building functions. Sascha Leiber et al. [10] proposed a novel visual appearance only based heating energy prediction method for single-family houses using powerful image analysis and computer vision techniques that can be used in widely distributed rural buildings in the north of China. The Tsinghua Building Energy Efficiency Research Center has established the China Building Energy Consumption Model (CBEM) that is based on energy intensity and macro-validated by statistical data [11], yielding a heating energy consumption of 201 Mtce for northern cities and towns in China in 2017, accounting for 21\% of building energy consumption.

However, some of these models are from a macro perspective, mainly aimed at fitting the historical data of national energy consumption and carbon emissions, to facilitate the study of the relationship between the energy sector and the overall economy. In addition, the economic development in northern China is not balanced, and the rural area is large. 
Some models do not separate the rural areas but focus on urban areas. It is impossible to calculate the heating energy consumption and carbon emissions in rural areas more accurately. At the same time, for different building types, accurate division is also very important.

\section{Method}

Based on the research on macro building energy consumption at home and abroad, this paper calculates the living and public building area by analyzing factors such as population, per capita living area and economic indicators. Starting from the terminal energy consumption, based on the characteristics of China's energy structure system and building energy consumption, combined with the design and actual operation characteristics of urban central heating and rural heating, this paper establishes a macro prediction calculation model of heating energy consumption of northern civil buildings based on the energy consumption intensity of per capita building area and unit building area. Combined with carbon emissions and future heating energy structure prediction in northern China, the model calculates the total amount of heating carbon emissions in the future, which provides data support for controlling building carbon emissions and guiding building energy efficiency. In the calculation process, considering the heating difference between urban and rural areas, the northern civil buildings are divided into urban buildings and rural residential buildings from the area. Urban buildings include urban residential buildings and public buildings. The total heating energy consumption of urban buildings, including residential buildings and public buildings, and rural residential buildings are calculated respectively, which realizes the attention to urban areas, rural areas and different types of buildings.

The calculation model constructed in this paper is based on the calculation method of building area and unit energy intensity, and after deriving the heating energy consumption, the corresponding carbon emission intensity is then calculated according to the energy structure and carbon emission coefficient. Firstly, the northern civil buildings are divided into urban buildings and rural residential buildings, among which urban buildings are further divided into residential buildings and public buildings. In calculating the building area, a more accurate calculation forecast is made for each type of building area by considering the influence of factors such as housing demand, economic and social development, land resource constraints and urbanization rate. Similarly, when calculating energy consumption intensity, it is necessary to combine factors such as heating methods, heat source efficiency, losses, etc., while taking into account changes in energy policies and changes in heating energy structures, in order to arrive at relatively accurate results. After calculating the floor area and energy consumption intensity, the total heating energy consumption in northern regions can be easily obtained; finally, the heating carbon emissions are calculated based on the energy structure and carbon emission coefficient. The calculation method is shown in Figure 1.

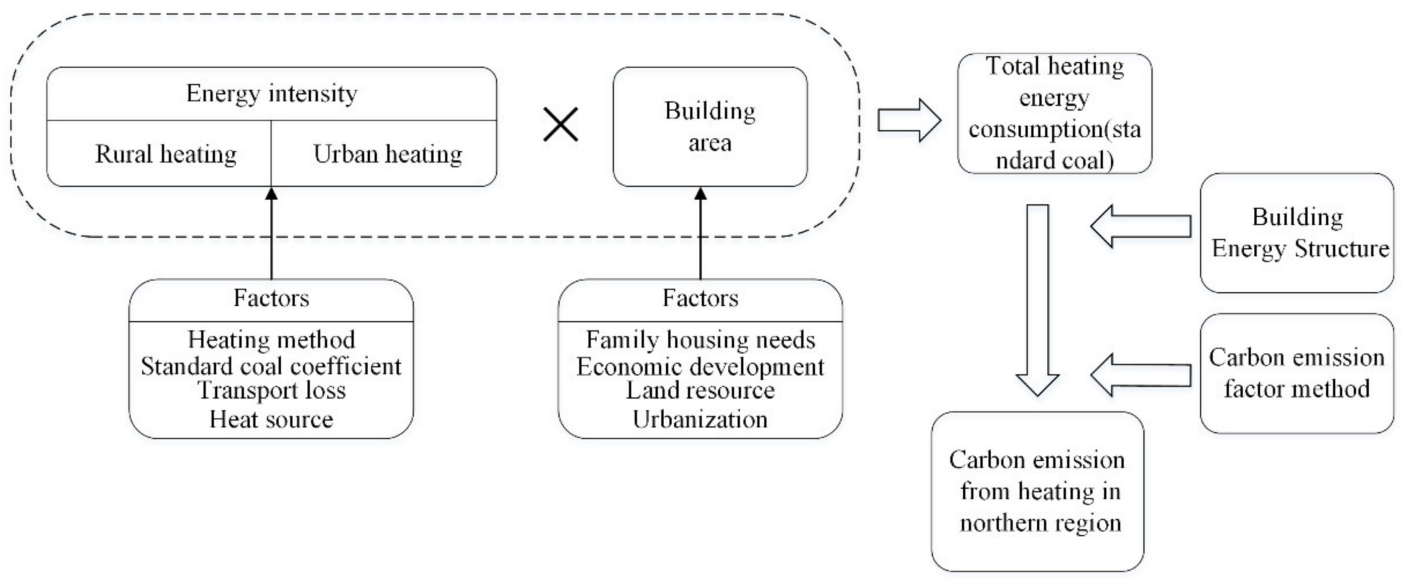

Figure 1. Heating energy consumption and carbon emission research method. 
The research flow of the article is shown in Figure 2, and the conclusion is in Section 7.

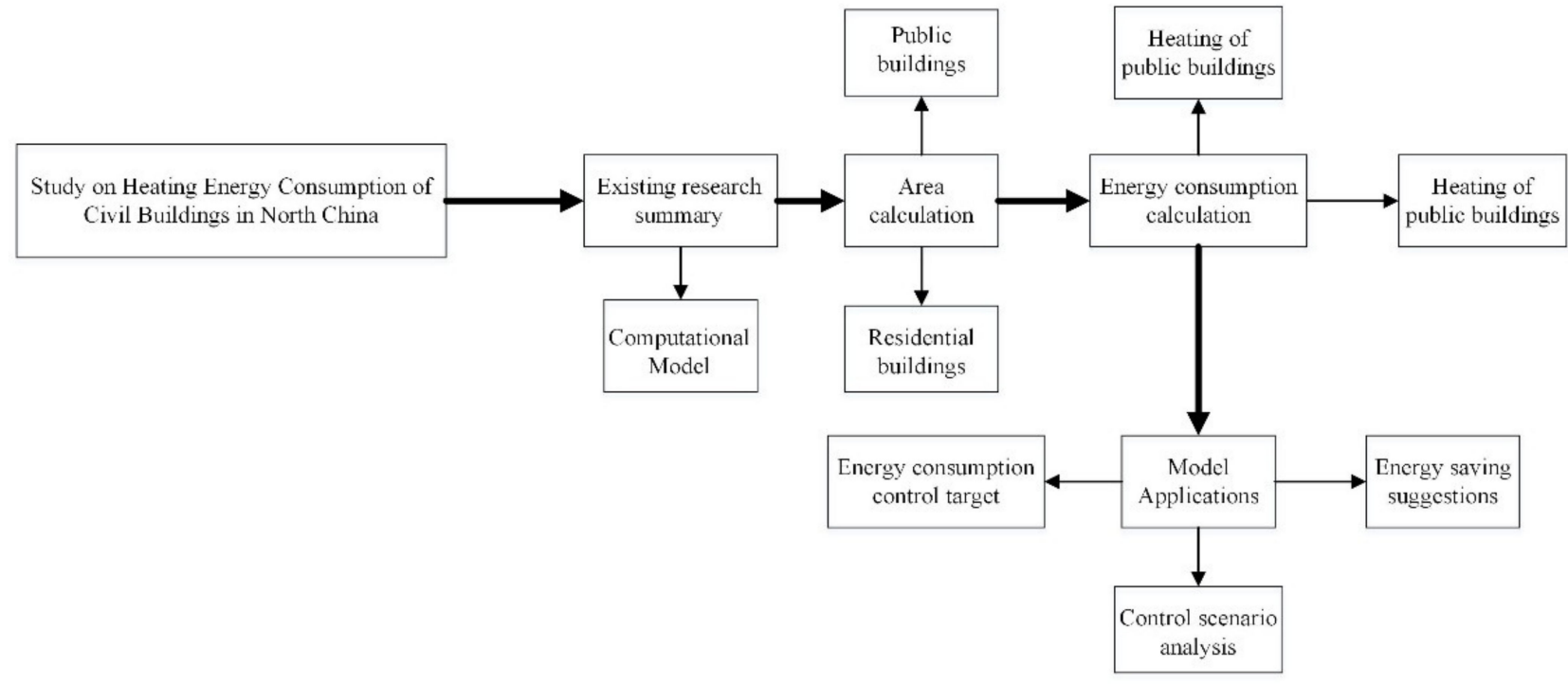

Figure 2. Article Research Flow Chart.

\section{Forecasting of Heating Area in Northern China}

Building area data are the working basis of building energy efficiency. Whether it is to calculate the total amount of building energy consumption, analyze energy-saving potential or formulate energy-saving goals, it must be based on building area data. However, because China's construction field only gathers statistics on the amount of new construction over the years and does not count the corresponding amount of demolition management, the current various types of building stock cannot be given directly by statistical data. Therefore, we can only calculate the floor area by other means and cannot give precise data. The current functional characteristics of civil buildings in China are divided into two categories for statistical analysis: residential buildings and public buildings.

\subsection{Residential Buildings}

\subsubsection{Residential Area Status}

Residential buildings can be divided into urban and rural residential buildings according to their geographical distribution and living habits. Different organizations have given different values of residential area per capita in China by sampling research or estimation methods. As shown in Figure 3, the data released by the National Bureau of Statistics [12,13] are the result of a sample survey of residential building area, based on the per capita residential area converted from the registered population. The Building Energy Efficiency Association [14] and the Building Energy Conservation Research Center of Tsinghua University [15] use the relevant data in the Statistical Yearbook to calculate the residential building area by using the 'fuzzy neural network' and 'existing + new construction-demolition' methods and then calculate the corresponding per capita residential building area according to the number of urban and rural residents.

There are three main reasons for the differences in the data of each agency: one is the data source- - the per capita area data of each agency are mostly the result of sample surveys or different methods based on historical data; the second is the statistical caliber of the population - the number of permanent residents and the registered population will lead to large differences in the per capita area; the third is about the scope of the residential area-the three concepts of building area, usable area and floor area are quite different. The residential area discussed in this article is the building area, which is analyzed and calculated according to the per capita residential area index of the permanent population. 

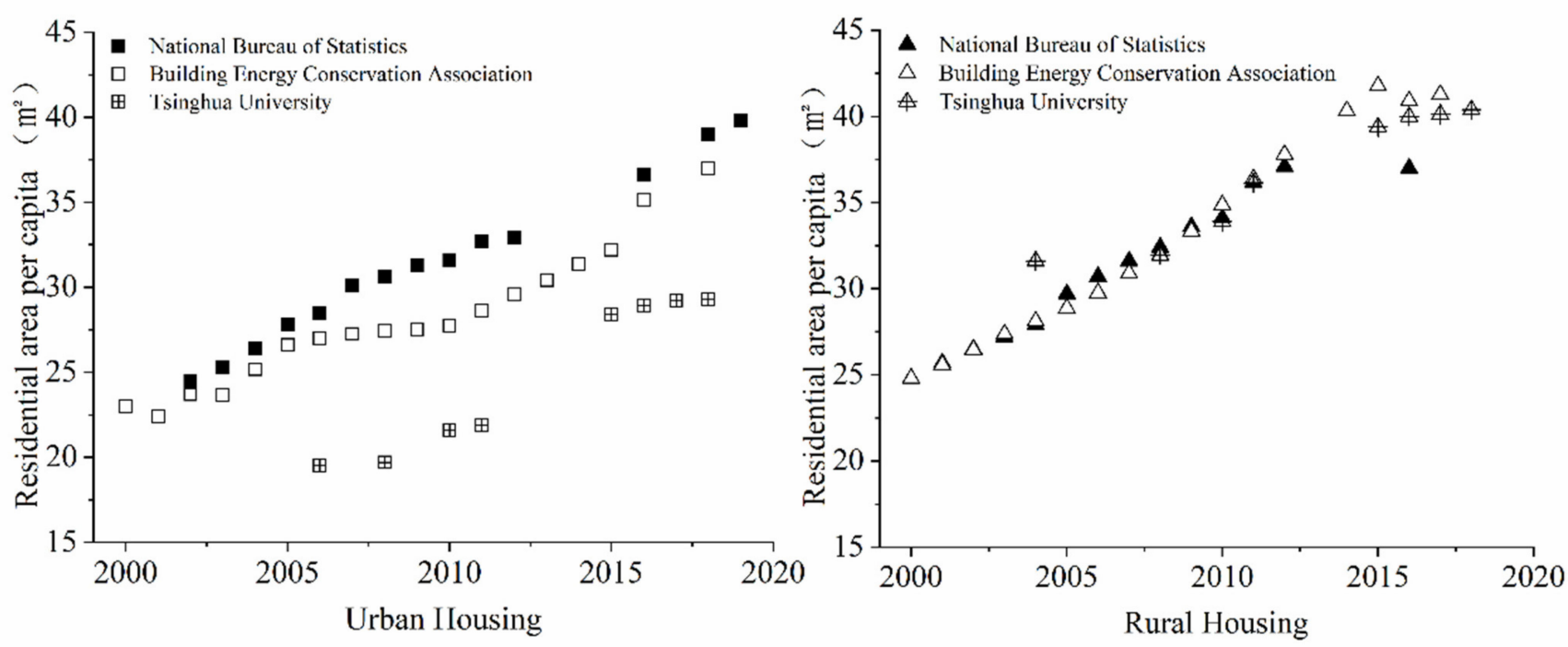

Figure 3. Comparison of calculated values of per capita residential area by different institutions.

With reference to the research data on residential building area by various institutions, using the number of permanent residents and the urbanization rate in the China Statistical Yearbook [16] over the years, the existing building area of urban and rural residential buildings can be calculated, as shown in Figure 4.

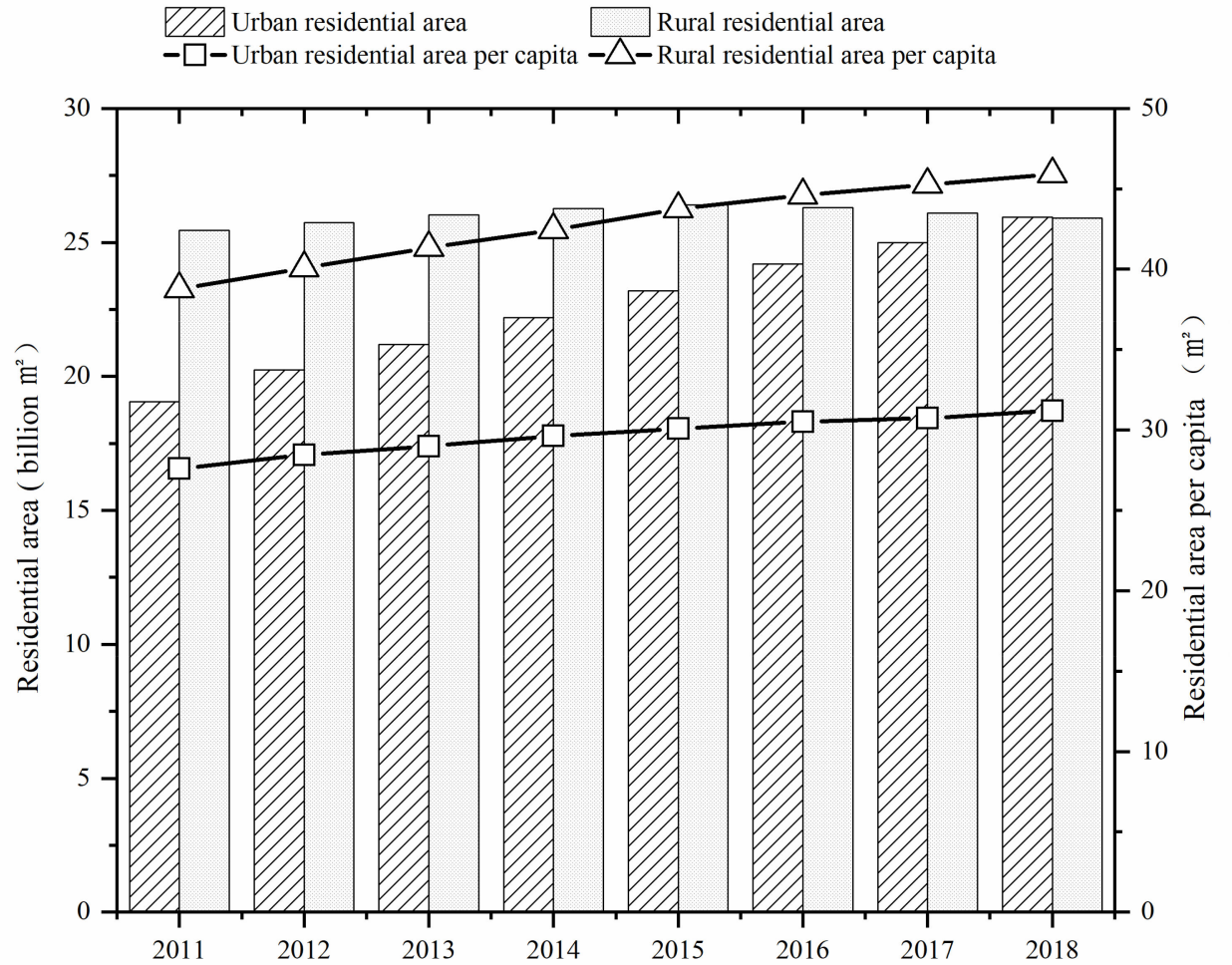

Figure 4. Urban and rural residential construction area and per capita residential area over the years.

\subsubsection{Per Capita Residential Space Needs and Constraints}

(1) GDP per capita. Foreign experience in housing development shows that the demand for housing area per capita gradually increases with urbanization. The global housing floor area per capita in each region is related to the degree of development, which is about $54 \mathrm{~m}^{2}$ in OECD member countries (about $45 \mathrm{~m}^{2}$ on average in Europe and Central Asia), about $30 \mathrm{~m}^{2}$ in Asia (except the Middle East) and about $20 \mathrm{~m}^{2}$ in sub- 
Saharan Africa, and databases of agencies such as Eurostat, the International Energy Agency and Japan's Ministry of Land, Infrastructure, Transport and Tourism show that the GDP per capita (PPP) in medium-sized developed countries is $\$ 20,000$ to $\$ 40,000$ when the housing floor area per capita is $32 \sim 45 \mathrm{~m}^{2}$.

(2) Resident income. With the development of the social economy, the increase in residents' income gradually increases the demand for housing. The China General Social Survey (CGSS) [17] conducted a questionnaire survey on the annual income and residential area of residents in China. The sample covered all provinces and cities in China except Hong Kong, Macao, Taiwan and Tibet. The sample selected in this paper is housing property owners with an annual income between $¥ 0.5$ and $¥ 250,000$ yuan in urban areas, and, after excluding missing values and outliers, the valid sample data are 1761 groups to analyze the demand for residential area per capita in urban areas in China. The relationship between the annual income of residents and housing floor area is shown in Figure 5. From the figure, it can be seen that the overall housing floor area increases with the increase in annual income. When the annual income of residents reaches $¥ 180,000$ (corresponding to a GDP per capita of about $\$ 40,000$ ), the household housing floor area is around $130 \mathrm{~m}^{2}$.

(3) Household size. The number of households has a significant positive effect on the housing demand of Chinese residents, and the explanatory power of the number of households on housing demand is significantly better than that of the total population indicator [18]. The survey results of the National Health Planning Commission's China Family Development Report show that the average size of urban households was 2.84 persons in 2015 [19], and two-person and three-person households accounted for $21.9 \%$ and $31.7 \%$ of the total number of surveyed households, respectively. Accordingly, it is deduced that when the income of residents grows to a certain extent, the expected value of future urban residential area per capita to meet the needs of families should be around $45 \mathrm{~m}^{2}$.

(4) Land resource constraints. According to China's territorial spatial planning, China's urban spatial index will be at 116,700 square kilometers in 2030 [20]. At present, the proportion of residential land in China accounts for about $31 \%$ of the urban construction land area [21], of which the ratio of residential to residential land is about $95 \%$. The proportion of residential land in China is too low, which is generally around $50 \%$ internationally, assuming that the proportion of residential land reaches $35 \%$ in 2030 and the proportion of residential remains unchanged. Research studies show that the average volume ratio of urban residential land is about 0.995 when the per capita energy consumption of residents is the lowest. Under the land resource constraint, a reasonable residential area per capita can be calculated by using the area and proportion of urban residential land and the population size, combined with the housing floor area ratio. The specific measurement method is shown in Equation (1). From this, it can be estimated that under the constraints of land resources and urbanization development, the housing floor area per capita should be controlled between 36 and $39 \mathrm{~m}^{2}$ in 2020-2030.

$$
a=A \cdot \rho_{r e} \cdot \rho_{r e, 1} \cdot \theta \div P
$$

where, $a$ is the per capita residential area in town, $\mathrm{m}^{2} /$ person; $A$ is the spatial control index of town, billion $\mathrm{m}^{2} ; \rho_{r e}$ is the proportion of residential land; $\rho_{r e, 1}$ is the proportion of residential to residential land; $\theta$ is the volume ratio of residential land in town; and $P$ is the number of resident population in town, billion.

Compared with urban residential area, the rural residential area constraint is more relaxed. Data from the China Statistical Yearbook show that the rural residential area per capita increased from 26.5 to $37.1 \mathrm{~m}^{2}$ / person between 2002 and 2012, an increase of 40.0\%, with an average annual increase of $3.4 \%$; the rural residential area per capita converted by the Standard Determination Institute [22] using the cumulative method of area over the years increased from 24.6 to $40.9 \mathrm{~m}^{2}$ /person between 2002 and 2010, an increase of 66.3\%, 
with an average annual growth rate of $5.2 \%$. With the development of urbanization and urban-rural integration, the growth rate of rural residential area per capita is expected to decrease in the future.

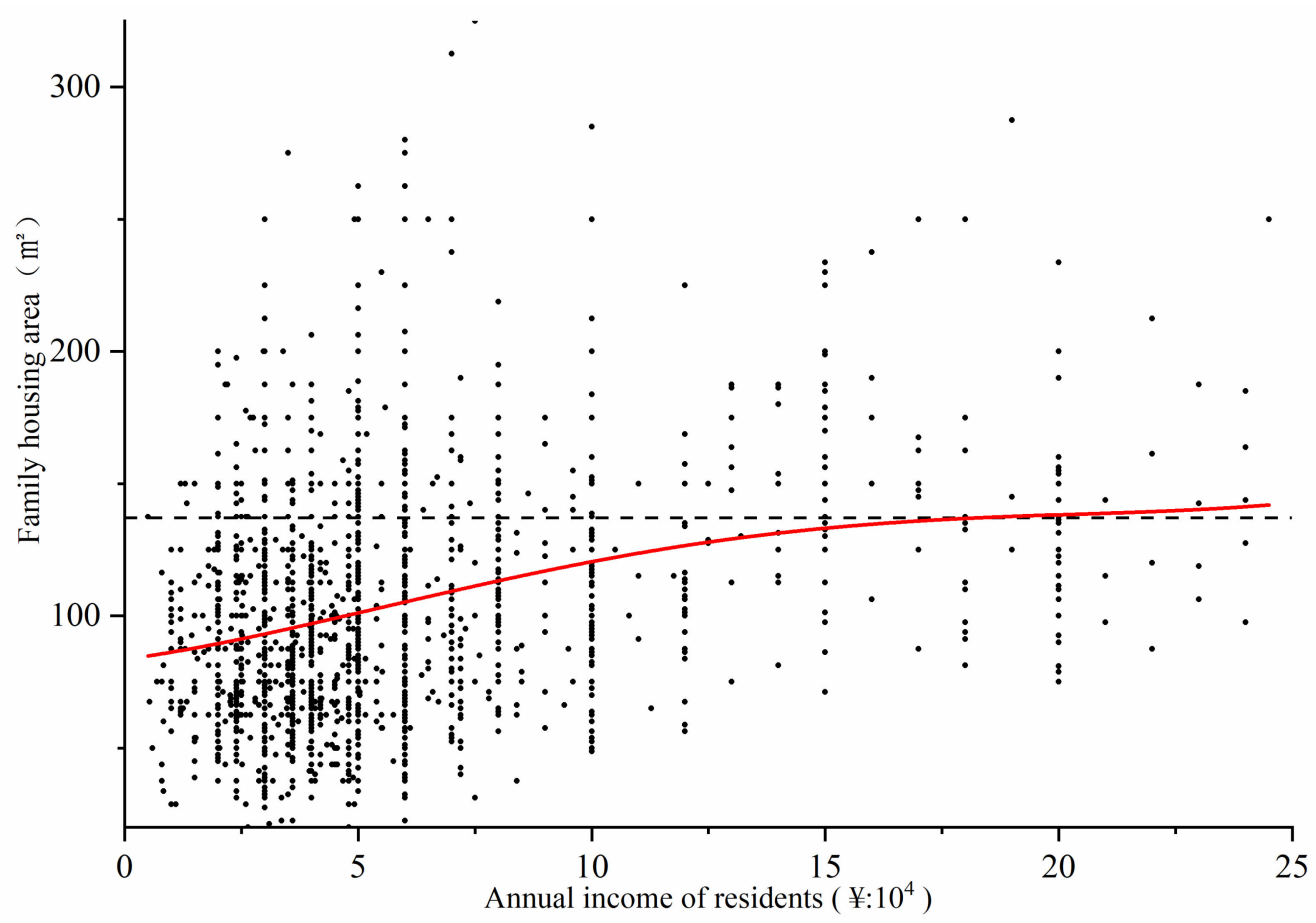

Figure 5. Residential annual income and housing construction area scatter plot.

\subsection{Public Buildings}

Because of the economic development of rural areas, there are fewer public buildings, so they are neglected, and all public buildings referred to in this paper refer to urban buildings. There are many types of public buildings, and the energy consumption of different types of public buildings varies greatly, so classifying public buildings is beneficial for the subsequent energy consumption research. Based on the consideration of building energy consumption and building quantity, combined with the data of various types of public buildings indexes in the China Statistical Yearbook, this paper will focus on the area calculation of medical buildings, office buildings, educational buildings, commercial buildings, cultural buildings and transportation buildings. Based on the current situation research and the existing data collected, this paper analyzes and refines the calculation methods of various types of public building area and the indexes that need to be predicted, as shown in Figure 6.

For all kinds of infrastructure and commercial public building area calculations, this paper refers to the model proposed by Gong et al. [23] to calculate and predict; the calculation method is shown in Figure 6. Other categories include public buildings such as gardens, communication buildings and religious buildings. The results of the census of large public buildings in Beijing [24] show that the public building area of 11 categories in 2005 was about 34 million $\mathrm{m}^{2}$. Using the data in the Statistical Yearbook [25], the estimated public building area in Beijing in the same year was 46.8 million $\mathrm{m}^{2}$, so the other categories of public buildings in Beijing that were not counted were about $25 \%$ of the total. In this paper, we will make reference to this ratio to estimate other types of public buildings.

\subsection{Civil Building Area Forecast}

With a population of only 1.4 billion in 2020 and a relatively low fertility rate, China has entered the era of negative population growth [26]. Famous population forecasters at home and abroad tend to forecast the peak year of China's population to be shifted forward, around 2023-2029. According to the results of a study by Professors Xianling 
Zhang and Zhenwu Zhai on negative population growth in China [27], if the total fertility rate is maintained at $1.6 \%$ in the future, negative population growth might occur in 2027. In this scenario, the total population of China will not exceed 1.41 billion in 2030.

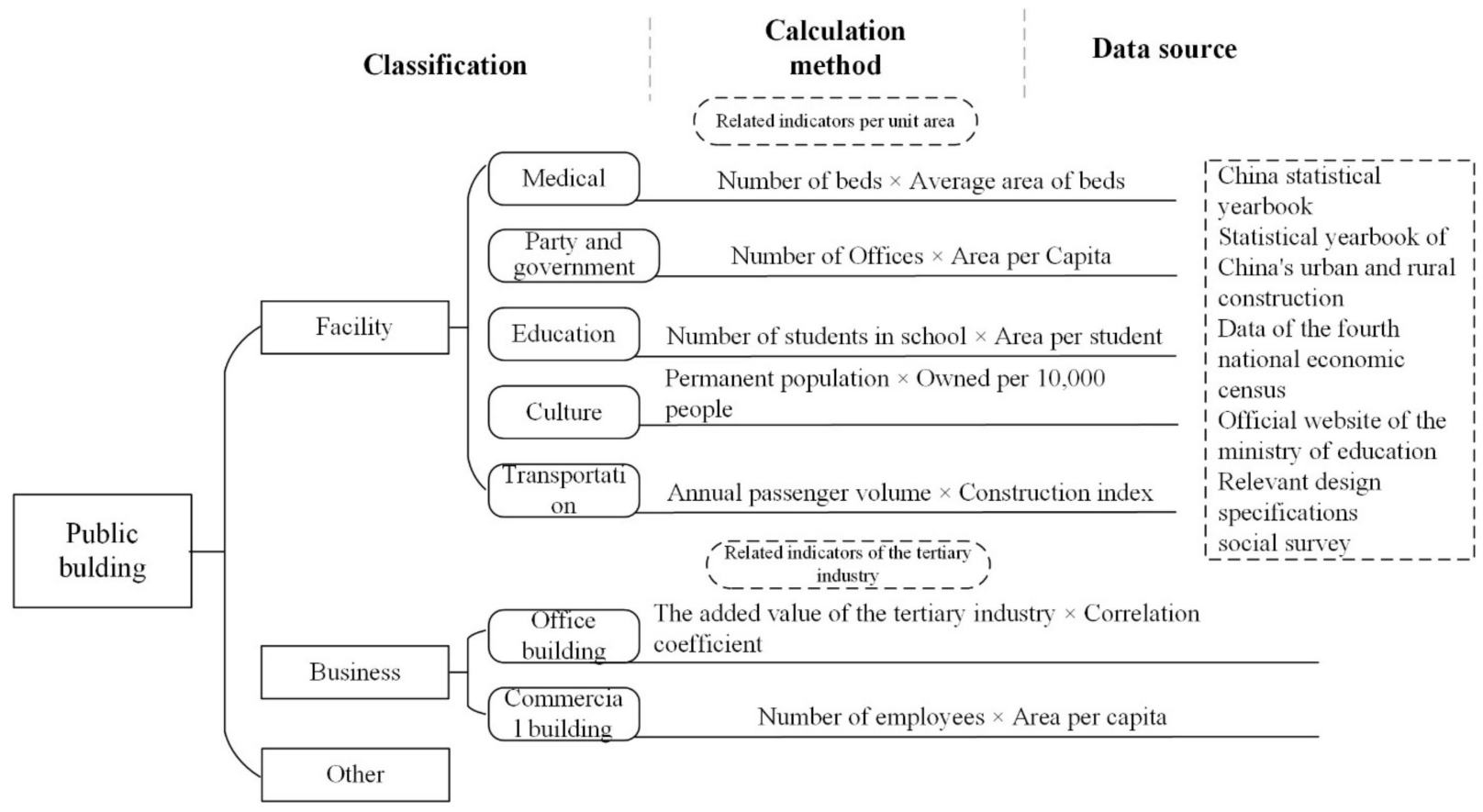

Figure 6. Classification of public buildings in China and calculation methods.

International experience shows that high economic growth is accompanied by rapid urbanization, and the urbanization process gradually slows down after the economic growth rate steps down. The 'saturation value' of the urbanization rate varies significantly from country to country. According to the research results of the Development Research Center of the State Council, the urbanization rate is about $65 \sim 75 \%$ when the per capita GDP is US\$10,000 20,000. From 2014 to 2020, China's urbanization rate will keep an average annual growth rate of about 1 percentage point, and the urbanization rate of the resident population will exceed $60 \%$ by 2020 [28].

The China Statistical Yearbook shows that in 2019 the urbanization rate of the permanent population in the country reached $60.6 \%$. Assuming that China's urbanization rate will continue to grow by $1 \%$ per year in the next 10 years, it will reach $70 \%$ in 2030 and a plateau of $75 \%$ in 2040 (referring to the experience of international urbanization rates, combined with the age structure of China's population, rural arable land and food, the constraints of production, rural labor and other aspects, we assume that the peak urbanization rate in China is $75 \%$ ). The future development trend of China's population and urbanization rate is shown in Figure 7. The total population will reach a peak of 1.412 billion in 2027, and the urbanization rate will enter a plateau of $75 \%$ in 2040 . At this time, the urban population will reach a peak of 1.03 billion, and the rural population will continue to decrease.

For urban dwellings, taking into account household housing demand, economic and social development and land resource constraints, this paper assumes that the future per capita dwelling area in China's urban areas will be between 32 and $42 \mathrm{~m}^{2}$. For rural dwellings, considering further urbanization development in the future, the growth rate of rural dwellings per capita will be reduced, and the rural dwelling area per capita is expected to reach a peak of $55 \mathrm{~m}^{2} /$ person in 2035. In summary, the prediction of residential area per capita in China in this paper is shown in Figure 7.

Based on historical data, with reference to the development trend of developed countries and combined with China's national conditions, this paper makes predictions for each type of public building area index in China in the future, as shown in Table 1. 


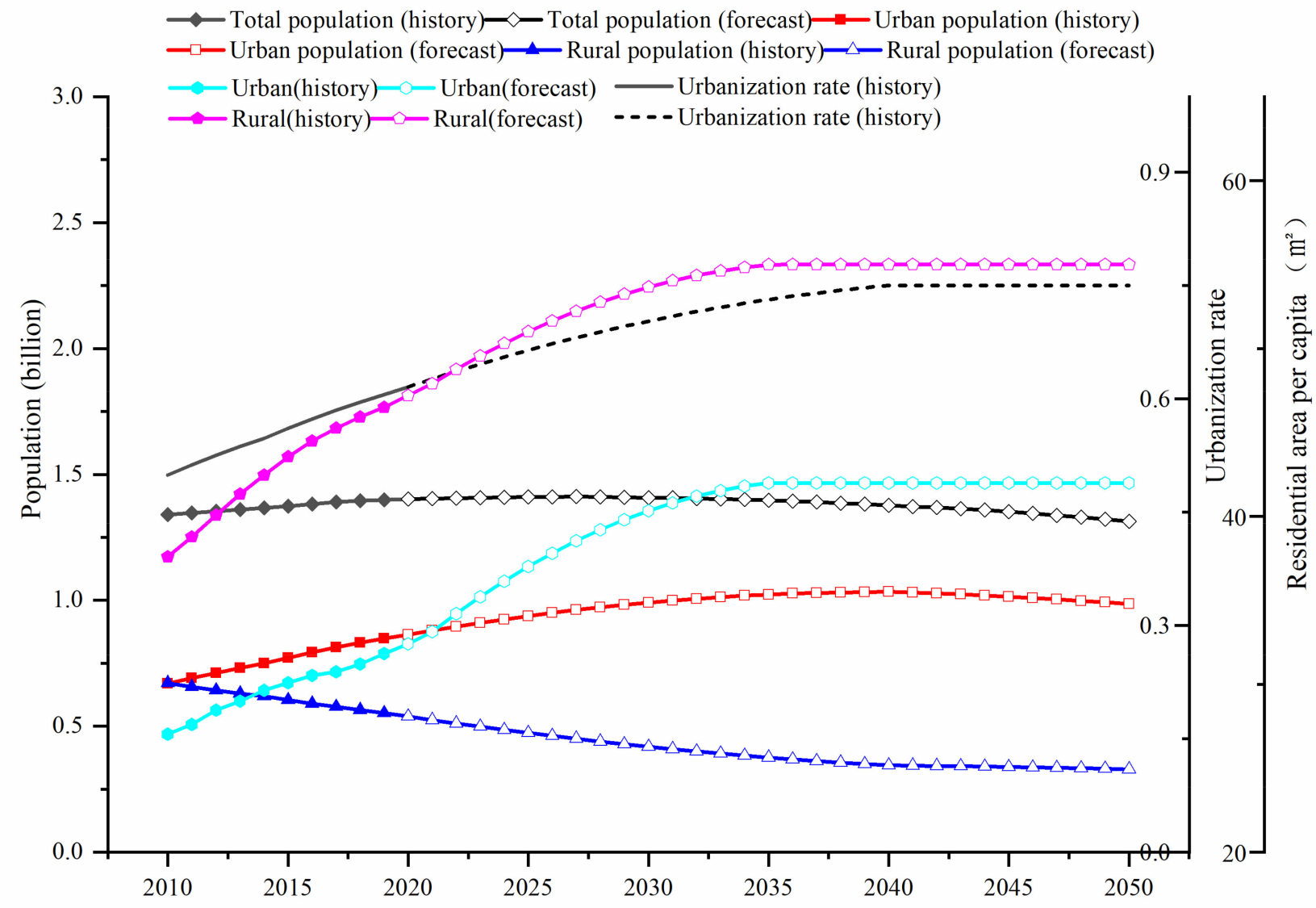

Figure 7. Forecast of future urbanization rate, corresponding population and residential area per capita in China.

Table 1. Forecast of future indicators for various types of public buildings in China.

\begin{tabular}{|c|c|c|c|c|c|}
\hline Building Type & Indicator & 2020 & 2030 & 2040 & 2050 \\
\hline \multirow{2}{*}{ Medical Building } & Number of beds (beds per 1000 people) & 6.0 & 8.5 & 9.0 & 7.5 \\
\hline & Average bed area $\left(\mathrm{m}^{2}\right)$ & 107 & 137 & 146 & 151 \\
\hline Party and & Number of employees (million) & 91.13 & 91.52 & 89.57 & 85.37 \\
\hline Government Building & Area per capita $\left(\mathrm{m}^{2}\right)$ & 33.0 & 37.6 & 39.9 & 40.0 \\
\hline Office Building & Value added of tertiary industry (trillion) & 60 & 132 & 227 & 332 \\
\hline \multirow{2}{*}{ Education Building } & Number of students (million) & 308.44 & 348.01 & 367.05 & 364.54 \\
\hline & Average student area ( $\mathrm{m}^{2} /$ person) & 13.5 & 14.3 & 14.8 & 15.0 \\
\hline Business- & Number of employees (million) & 5.17 & 8.23 & 8.86 & 8.91 \\
\hline Accommodation & Area per capita $\left(\mathrm{m}^{2} /\right.$ person $)$ & 32 & 62 & 70 & 75 \\
\hline \multirow[b]{2}{*}{ Business-Restaurant } & Number of employees (million) & 6.31 & 7.01 & 7.04 & 6.81 \\
\hline & Area per capita $\left(\mathrm{m}^{2} /\right.$ person $)$ & 35 & 56 & 62 & 65 \\
\hline \multirow{2}{*}{ Business-Wholesale } & Number of employees (million) & 21.13 & 23.47 & 24.54 & 25.32 \\
\hline & Area per capita $\left(\mathrm{m}^{2} /\right.$ person $)$ & 36 & 39 & 40 & 40 \\
\hline \multirow{2}{*}{ Business-Retail } & Number of employees (million) & 21.03 & 23.43 & 24.36 & 23.79 \\
\hline & Area per capita $\left(\mathrm{m}^{2} /\right.$ person $)$ & 65 & 73 & 78 & 80 \\
\hline Cultural Building & Owned per 10,000 people $\left(\mathrm{m}^{2}\right)$ & 480 & 593 & 648 & 801 \\
\hline Transportation-Passenger Terminal & Annual passenger volume (billion) & 17.1 & 15 & 13.5 & 12.8 \\
\hline Transportation-Terminal & Annual passenger volume (billion) & 0.63 & 0.75 & 0.85 & 0.92 \\
\hline
\end{tabular}

According to the forecasts of population, urbanization rate and various civil building related index parameters, the forecast results of the total scale of urban residential, rural residential and public buildings in China in the future are shown in Table 2. 
Table 2. Various types of construction area in China in the future (billion $\mathrm{m}^{2}$ ).

\begin{tabular}{ccccc}
\hline Building Type & $\mathbf{2 0 2 0}$ & $\mathbf{2 0 3 0}$ & $\mathbf{2 0 4 0}$ & $\mathbf{2 0 5 0}$ \\
\hline Urban residence & 27.6 & 39.9 & 43.4 & 41.4 \\
Rural residence & 25.3 & 22.4 & 18.9 & 18.1 \\
Public building & 15.2 & 19.7 & 21.8 & 21.9 \\
Total area & 68.1 & 82.1 & 84.2 & 81.3 \\
\hline
\end{tabular}

Based on the historical population data of each province in the China Statistical Yearbook, combined with the forecast of the future population of each province in the report of the calibration institute, the proportion of the population of each province to the total population can be obtained. The civil building area in China is split according to the proportion of population, and the various types of civil building area in the northern region are shown in Table 3.

Table 3. Future projections of various types of floor space in northern China (billion $\mathrm{m}^{2}$ ).

\begin{tabular}{ccccc}
\hline Building Type & $\mathbf{2 0 2 0}$ & $\mathbf{2 0 3 0}$ & $\mathbf{2 0 4 0}$ & $\mathbf{2 0 5 0}$ \\
\hline Urban residence & 11.6 & 16.7 & 18.0 & 16.9 \\
Rural residence & 10.6 & 9.4 & 7.8 & 7.4 \\
Public building & 6.4 & 8.2 & 9.0 & 8.9 \\
Total area & 28.6 & 34.3 & 34.8 & 33.2 \\
\hline
\end{tabular}

\subsection{Heating Area in Northern Towns}

The building area in urban areas is the sum of residential area and public building area in towns and cities, and the total number of public buildings in rural areas is smaller and ignored for the time being. Heating in northern towns includes the centralized heating area and a part of the decentralized heating area that is not covered by the centralized heating pipeline network. According to the table of centralized heating in cities in various regions in the China Statistical Yearbook, it was calculated that the centralized heating rate in northern urban areas of China was about $65 \%$ in 2018. However, the non-operating centralized heating data are not counted in the Statistical Yearbook, and, referring to the status of the centralized heating area in the special planning of heating in each region [29,30], the comparison reveals that the planned heating area is about 1.2 times the area in the Statistical Yearbook. This leads to a correction of the centralized heating area in northern towns and cities, which yielded a centralized heating rate of about $85 \%$ and a centralized heating area of 13.6 billion $\mathrm{m}^{2}$ in 2018. According to the current heating situation and heating plan in northern China, it is assumed that the centralized heating rate in northern urban areas will reach $90 \%$ in 2035 and $95 \%$ in 2050. The prediction of heating area in northern urban areas of China in the future in this paper is shown in Table 4.

Table 4. Future heating area forecast in northern urban areas of China (billion $\mathrm{m}^{2}$ ).

\begin{tabular}{ccccc}
\hline & $\mathbf{2 0 2 0}$ & $\mathbf{2 0 3 0}$ & $\mathbf{2 0 4 0}$ & $\mathbf{2 0 5 0}$ \\
\hline Heating area in & 18.0 & 24.9 & 27.0 & 25.8 \\
northern towns & 15.4 & 22.1 & 24.8 & 24.5 \\
\hline
\end{tabular}

\section{Northern Civil Building Heating Energy Consumption}

\subsection{Energy Consumption in Northern Towns}

The heat consumed by building heating is included in the building heating energy consumption according to the actual heat source and the type of energy consumed by the transmission and distribution system, as well as the electricity, gas or standard coal converted according to the heat provided and the actual energy efficiency of the system [31]. The energy conversion in China is mainly based on the conversion of low-level calories of various types of energy into the standard coal equivalent, and, according to the appendix of 
the China Energy Statistical Yearbook, the conversion coefficients of various types of energy into standard coal are shown in Table 5. The coal consumption method for electricity supply refers to the amount of standard coal consumed by thermal power plants for every $1 \mathrm{kWh}$ of electricity supplied to the outside, which will be used as the standard coal equivalent coefficient for electricity conversion in this paper.

Table 5. Standard coal coefficients of various energy conversions.

\begin{tabular}{|c|c|c|c|c|c|}
\hline Energy Type & Raw Coal & Liquefied Petroleum Gas & Natural Gas & $\begin{array}{l}\text { Thermal Power (Standard } \\
\text { Coal Equivalent) }\end{array}$ & $\begin{array}{l}\text { Electricity (Coal Consumption } \\
\text { for Power Supply) }\end{array}$ \\
\hline $\begin{array}{l}\text { Conversion factor to } \\
\text { standard coal }\end{array}$ & $0.7143 \mathrm{kgce} / \mathrm{kg}$ & $1.7143 \mathrm{kgce} / \mathrm{kg}$ & $1.3 \mathrm{kgce} / \mathrm{m}^{3}$ & $0.03412 \mathrm{kgce} / \mathrm{MJ}$ & $0.31 \mathrm{kgce} / \mathrm{kWh}$ \\
\hline
\end{tabular}

\subsubsection{Heat Source}

The heat source of heating in northern cities and towns in China presents a pattern of combined heat and power, with coal-fired boilers as the leading source, and a combination of multiple energy sources and multiple heat sources, mainly divided into centralized heating and decentralized heating. At present, centralized heating can be divided into cogeneration, regional boilers, heat pumps, etc. According to the heating method, decentralized heating is mainly gas wall-hung furnaces, household coal-fired furnaces and direct electric heating. Clean heating uses clean energy such as natural gas, electricity, geothermal, biomass, solar energy, industrial waste heat, clean coal (ultra-low emissions) and nuclear energy to achieve low emissions and low energy consumption through high-efficiency energy-use systems. The heating energy used in northern areas of China is mainly coalfired, and, at the end of 2016, the coal-fired heating area accounted for about $83 \%$ of the total heating area, while natural gas, electricity, geothermal energy, biomass, solar energy and industrial waste heat together accounted for about $17 \%$, with renewable energy reaching $4 \%$ [32]. The current heating methods in northern cities and towns are mainly cogeneration, boilers, wall-hung furnaces and auxiliary electric-driven heat pumps. The efficiency of heat sources for different heating methods in northern China was calculated using the available energy apportionment method [32], and the calculation results and the proportion of heat sources used are shown in Table 6.

Table 6. Efficiency and proportion of heat sources for different heating methods in 2018.

\begin{tabular}{ccccccc}
\hline & \multicolumn{3}{c}{ Centralized Heating } & \multicolumn{2}{c}{ Decentralized Heating } \\
\cline { 2 - 5 } Heating Method & $\begin{array}{c}\text { Coal-Fired } \\
\text { Cogeneration }\end{array}$ & $\begin{array}{c}\text { Gas-Fired } \\
\text { Cogeneration }\end{array}$ & $\begin{array}{c}\text { Coal-Fired } \\
\text { Boiler }\end{array}$ & Gas Boiler & $\begin{array}{c}\text { Centralized } \\
\text { Heat Pump }\end{array}$ & $\begin{array}{c}\text { Gas Wall-Mounted } \\
\text { Furnace }\end{array}$ \\
\hline $\begin{array}{c}\text { Heat source } \\
\text { efficiency } \\
\text { (kgce/GJ) }\end{array}$ & 21 & 23 & 40 & 35 & 28 & 32 \\
Proportion (\%) & 45 & 3 & 30 & 2.5 & 1 & 44 \\
\hline
\end{tabular}

\subsubsection{Energy Consumption for Transmission and Distribution}

(1) Transmission and distribution consumption. The electricity consumption of the heating system pipe network pumps during the heating period includes the electricity consumption of the circulating pumps at the heat source, the circulating pumps at the heat station and the circulating pumps on the heat consumer side of the heat pump heating. Research shows that the current electricity consumption of the secondary network of heat stations in northern areas is between 1 and $4 \mathrm{kWh} / \mathrm{m}^{2}$, which has a large potential for energy saving [33]. Unreasonable water pump selection, inlet and outlet pressure losses and excessive secondary network flow are the causes of high transmission and distribution power consumption.

(2) Heat loss of pipe network. The delivery efficiency of China's heating pipe network is between $70 \%$ and $80 \%$, while the delivery efficiency of foreign countries reaches 92-95\% [34]. The reason for such a large gap is that the heat loss of the pipe network abroad is only insulation loss, while China has insulation loss, imbalance loss and leakage loss, of which imbalance loss is more serious. The heat loss of the primary network 
of urban heating is about $10 \%$, while the secondary network has serious running and leaking phenomena due to the early construction age and insufficient maintenance, and the average heat loss is about 20\% [35]. According to the Technical Specification for Energy Conservation and Renovation of Heating Systems, the transmission efficiency of the primary heating network shall not be less than $95 \%$, and the transmission efficiency of the secondary heating network shall not be less than $92 \%$ [36]. The clean heating plan also puts forward energy-saving renovation requirements for heating pipe networks, with $84,000 \mathrm{~km}$ of new heating pipe networks in northern areas and $50,000 \mathrm{~km}$ of heating pipe network renovation completed-16,000 km of primary networks and $34,000 \mathrm{~km}$ of secondary networks renovated.

\subsubsection{Building Heating Consumption}

JGJ 26-2010 gives the specific calculation formula of the heat consumption index of buildings, which is very detailed, but the amount of data is too much. In order to facilitate the calculation, this study simplifies the calculation method of the heat consumption index of buildings in this standard, see Equation (2). Multiplying by the heating hours results in the building heat consumption, see Equation (3).

$$
\begin{gathered}
q_{H}=\left(K+C_{p} \cdot \rho \cdot N \cdot I \cdot \varepsilon\right)\left(t_{n}-t_{e}\right)-q_{I . H} \\
Q_{H}=q_{H} \cdot T_{H}
\end{gathered}
$$

where $q_{H}$ is the heat consumption index of the building, $\mathrm{W} / \mathrm{m}^{2} ; K$ is the integrated heat transfer coefficient of the building envelope (obtained by converting the average heat transfer coefficient of windows, walls, doors and roofs), $\mathrm{W} /\left(\mathrm{m}^{2}-\mathrm{K}\right) ; C_{p}$ is the specific heat capacity of air, taken as $0.28 \mathrm{Wh} /(\mathrm{kg}-\mathrm{K}) ; \rho$ is the density of air (taken as the value under the temperature $\left.t_{e}\right), \mathrm{kg} / \mathrm{m}^{3} ; N$ is the number of air changes, taken as $0.51 / \mathrm{h} ; I$ is the building floor height, taken as $3 \mathrm{~m} ; \varepsilon$ is the ventilation volume correction coefficient, taken as $0.6 ; t_{n}$ is the calculated indoor temperature, taken as $18{ }^{\circ} \mathrm{C} ; t_{e}$ is the average outdoor temperature during the heating period $\left({ }^{\circ} \mathrm{C}\right) ; q_{I . H}$ is the unit building area and unit time- the internal heat gain of the building is taken as $3.8 \mathrm{~W} / \mathrm{m}^{2} ; Q_{H}$ is the heat consumption of the building, $\mathrm{kWh} / \mathrm{m}^{2}$; and $T_{H}$ is the complete heating time in a heating period, $\mathrm{h}$.

The northern region of China includes two climatic zones of severe cold and cold areas, where the outdoor temperature, heating hours and thermal performance of the envelope differ greatly. According to JGJ 26-2010, the average outdoor temperature during the heating period in the cold region (Inner Mongolia, Liaoning, Jilin, Heilongjiang, Qinghai and Xinjiang) is $-5.6^{\circ} \mathrm{C}$ and the average heating duration is 174.1 days; the average outdoor temperature during the heating period in the cold region (Beijing, Tianjin, Hebei, Shanxi, Shandong, Henan, Shaanxi, Gansu and Ningxia) is $-0.76{ }^{\circ} \mathrm{C}$ and the average heating duration is 121.7 days [37]. The area ratio of the two climatic zones, harsh and cold, is estimated to be 2.8:7.2 by population ratio. Due to the geographical location of the severe cold regions, the heat transfer coefficient of their building envelopes is lower than that of the cold regions by $0.1-0.3 \mathrm{~W} /\left(\mathrm{m}^{2}-\mathrm{K}\right)$ [38]. According to the current rate of building energy renovation, the proportion of energy-efficient buildings to urban civil construction area exceeded 50\% in 2016 [32], and the proportion of energy-efficient buildings would have been about $60 \%$ in 2018 . The comprehensive relevant data above, according to Equations (2) and (3), can achieve the current building heat consumption in the cold and severe cold areas of northern towns in China, as shown in Table 7.

\begin{tabular}{|c|c|c|c|c|}
\hline Climate Zone & Building Type & $\begin{array}{l}\text { Average Heat Transfer } \\
\text { Coefficient }\left(\mathrm{W} /\left(\mathrm{m}^{2} \cdot \mathrm{K}\right)\right)\end{array}$ & $\begin{array}{c}\text { Building Heat } \\
\text { Consumption }\left(\mathrm{kWh} / \mathrm{m}^{2}\right)\end{array}$ & $\begin{array}{c}\text { Average Heat } \\
\text { Consumption }\left(\mathrm{kWh} / \mathrm{m}^{2}\right)\end{array}$ \\
\hline \multirow{2}{*}{ Severe cold area } & Non-Energy-Efficient Building & 1.1 & 125.4 & \multirow{4}{*}{78.3} \\
\hline & Energy-Efficient Building & 0.75 & 89.5 & \\
\hline \multirow{2}{*}{ Cold area } & Non-Energy-Efficient Building & 1.3 & 78.0 & \\
\hline & Energy-Efficient Building & 0.95 & 58.1 & \\
\hline
\end{tabular}

Table 7. Heat consumption of buildings in severe cold and cold areas of northern towns in China, 2018. 


\subsubsection{Calculation Method of Heating Energy Consumption in Northern Towns}

The heating energy consumption (excluding renewable) in northern towns is calculated as shown in Equations (4)-(6).

$$
\begin{gathered}
e_{c}=\left(\frac{Q_{H}}{\eta_{1} \cdot \eta_{2}}\right) \times \sum_{i}\left(p_{c, i} \cdot k_{c, i}\right) \\
e_{d}=Q_{H} \times \sum_{j}\left(p_{d, j} \cdot k_{d, j}\right) \\
E_{H}=\left(e_{c} \cdot A_{c}+e_{d} \cdot A_{d}\right) \times\left(1-\alpha_{r e}\right)
\end{gathered}
$$

where $e_{c}$ is the energy intensity of central heating, $\mathrm{kgce} /\left(\mathrm{m}^{2}-\mathrm{a}\right) ; \eta_{1}$ is the primary network efficiency; $\eta_{2}$ is the secondary network efficiency; $Q_{L}$ is the transmission and distribution consumption loss, $\mathrm{kWh} / \mathrm{m}^{2} ; p$ is the heat source efficiency of different heating methods, kgce/GJ; $k$ is the proportion of different heating methods used; $i$ is the different central heating methods (coal-fired cogeneration, gas-fired cogeneration, coal-fired boiler, gas boiler, centralized heat pump); $j$ is the different decentralized heating methods (gas wall-hung stove, electric heating); $e_{d}$ is the energy intensity of decentralized heating, $\mathrm{kgce} /\left(\mathrm{m}^{2}-\mathrm{a}\right) ; E_{H}$ is the total energy consumption of heating in northern towns, billion kgce; $A_{c}$ is the centralized heating area, billion $\mathrm{m}^{2} ; A_{d}$ is the decentralized heating area, billion $\mathrm{m}^{2}$; and $\alpha_{r e}$ is the proportion of renewable energy for heating. When the national average coal consumption for electricity supply is $310 \mathrm{kgce} / \mathrm{kWh}$, the above formula can be used to calculate that the current energy consumption intensity of centralized heating in China is $11.0 \mathrm{kgce} /\left(\mathrm{m}^{2}-\mathrm{a}\right)$, the energy consumption intensity of decentralized heating is $13.3 \mathrm{kgce} /\left(\mathrm{m}^{2}-\mathrm{a}\right)$, the average energy consumption intensity of urban heating is $11.4 \mathrm{kgce} /\left(\mathrm{m}^{2}-\mathrm{a}\right)$ and the total energy consumption of urban heating in northern areas is 180 Mtce.

\subsection{Northern Rural Heating Energy Consumption}

The type of energy in China's rural areas is mainly coal-fired and biomass (straw, fuel wood, biogas), and, with the promotion of clean energy, the proportion of electricity, natural gas and other energy sources is gradually increasing. Most of the rural areas in the north are decentralized for heating, with a large number of earth beds, stoves and earth heaters, and energy use is mainly coal and biomass. The cost of clean energy is high, and only a few rural houses use natural gas, electric energy and renewable energy for heating. The thermal performance of the envelope structure is poor, and only $20 \%$ of rural heating buildings have taken energy-saving measures. At present, the ratio of coal to biomass energy use in rural winter heating energy consumption in northern areas is about 3:1, and the average heating energy intensity is about $5 \mathrm{kgce} /\left(\mathrm{m}^{2}-\mathrm{a}\right)$ except for biomass $[39,40]$.

The calculation of energy consumption for heating rural dwellings is shown below:

$$
E_{r}=e_{r} \times A_{r}
$$

where $E_{r}$ is the total energy consumption of rural residential heating, billion kgce; $e_{r}$ is the energy consumption intensity of heating, $\mathrm{kgce} /\left(\mathrm{m}^{2}-\mathrm{a}\right)$; and $A_{r}$ is the area of rural residential houses in northern areas, billion $\mathrm{m}^{2}$. By analyzing the various rural energy uses, using Equation (7), we can calculate the residential heating energy intensity of $5.3 \mathrm{kgce} /\left(\mathrm{m}^{2}-\mathrm{a}\right)$ and the total energy consumption of 57.54 Mtce in 2018 in rural areas in northern China.

\section{Scenario-Based Analysis for Predicting Building Heating Energy Consumption in Northern Regions}

\subsection{Scenario Construction}

Using the 2018 energy intensity data as a benchmark, the future energy intensity for heating buildings in the north is set under three scenarios: (1) baseline control, i.e., development according to the current control measures; (2) medium control, i.e., adopting slightly stricter control measures than the benchmark scenario; (3) strict control, i.e., stricter measures are taken to control energy consumption intensity. 
The energy intensity settings for the three future scenarios are shown in Table 8, and the settings are described below.

(1) Prediction of energy consumption intensity of heating in northern towns. China is currently continuing to promote heating reform in northern cities and towns, and energy-saving efforts are being promoted in three areas: heat sources, heat networks and heat users. In terms of heating heat source, the proportion of centralized heating will be further increased, expanding from cities to urban and rural areas. Considering the requirements of the clean heating policy, centralized heating will be dominated by high-efficiency cogeneration, and small- and medium-sized coal-fired boilers will be gradually replaced. Decentralized heating will be dominated by gas wall-hung boilers, and electric energy will be mainly used for all kinds of electric-driven heat pump heating. In addition, the proportion of renewable energy for heating will continue to increase, and the demand for primary energy such as coal and natural gas will decline. For the transmission and distribution network, with the energysaving transformation of old primary and secondary pipeline networks and heat exchange stations, the efficiency of the pipeline network will gradually improve, and the heat loss and electricity consumption of transmission and distribution will be reduced. For building terminals, energy-saving renovation of existing buildings will be accelerated, and for new buildings $65 \%$ or even $75 \%$ energy-saving standards will be strictly enforced to reduce the heat demand for heating at the user end. Referring to the requirements of the Energy Consumption Standard for Civil Buildings (GB/T 51161-2016) for the design value of heating energy intensity, the constrained value of centralized heating energy intensity is $6.8 \mathrm{kgce} /\left(\mathrm{m}^{2}-\mathrm{a}\right)$ and the guide value is $3.6 \mathrm{kgce} /\left(\mathrm{m}^{2}-\mathrm{a}\right)$ in Shijiazhuang City, Hebei Province, for example. In this paper, it is assumed that the heating energy intensity will reach the standard constraint level in 2030 under the baseline control and will decrease to $5.3 \mathrm{kgce} /\left(\mathrm{m}^{2}-\mathrm{a}\right)$ in 2050 ; under the medium control, it is controlled at about $4.3 \mathrm{kgce} /\left(\mathrm{m}^{2}-\mathrm{a}\right)$ in 2050 ; and under the strict control, it approaches the standard guideline level and decreases to $3.9 \mathrm{kgce} /\left(\mathrm{m}^{2}-\mathrm{a}\right)$ in 2050.

(2) Prediction of energy consumption intensity of rural residential heating. With the continuous development of the rural economy and the improvement of the urbanization level, the demand for rural heating is increasing, and, when urbanization reaches a high level, the standard of living in rural areas should not be much different from that in cities and towns, but, due to the larger residential area per capita in rural areas, the building energy efficiency is backward and contains energy consumption for split heating, thus the intensity of energy consumption for heating in rural buildings will gradually rise. If our government can strengthen the regulation and guidance of rural energy use in the future, focus on promoting the use of renewable energy sources such as biomass, biogas and the development of photovoltaic and solar thermal technologies to replace some of the energy consumption increased by the improvement in the living standards of rural residents, the energy intensity of rural residential heating is expected to be controlled. In this paper, we assume that under the baseline control, the energy intensity of rural residential heating will increase rapidly, increasing by $19 \%$ to $6.3 \mathrm{kgce} /\left(\mathrm{m}^{2}-\mathrm{a}\right)$ in 2030 and $7.1 \mathrm{kgce} /\left(\mathrm{m}^{2}-\mathrm{a}\right)$ in 2050 ; under the medium control scenario, the energy intensity will increase slowly, reaching $6.6 \mathrm{kgce} /\left(\mathrm{m}^{2}-\mathrm{a}\right)$ in 2050 ; and under the strict control, the energy intensity of rural houses will increase slowly by $19 \%$ by 2030 and will be controlled at about $6.1 \mathrm{kgce} /\left(\mathrm{m}^{2}-\mathrm{a}\right)$ in 2050 .

\subsection{Prediction Results of Building Heating Energy Consumption under Different Scenarios}

(1) Baseline control scenario. Although the intensity of heating energy consumption in rural dwellings is increasing, due to the decreasing residential area, heating energy consumption in rural dwellings will peak at about 59.92 Mtce in 2026 and is expected to be controlled to 52.3 Mtce in 2050. Heating energy consumption in northern towns is decreasing year by year with the implementation of heating energy conservation 
policies and may be reduced to 122 Mtce in 2050. The total heating energy consumption in the north will peak in 2025 at about 237 Mtce.

(2) Medium control scenario. The energy consumption for heating in northern towns will be about 153 Mtce in 2030 and may decrease to 100 Mtce in 2050, a $45 \%$ reduction from 2018. Heating energy consumption in rural dwellings will peak at 58.57 Mtce in 2022 and then decline continuously under various energy efficiency measures to 56.59 Mtce in 2030 and 48.39 Mtce in 2050. The total heating energy consumption in the whole northern region will decrease to 210 Mtce in 2030 and to about 148 Mtce in 2050 .

(3) Strict control scenario. The energy consumption for future heating in northern areas under strict control scenarios is decreasing. Heating energy consumption in northern cities and towns may reach 141 Mtce in 2030 and be as low as 0.90 Mtce in 2050, with significant energy savings. Rural heating energy consumption will drop to $54.76 \mathrm{Mtce}$ in 2030 and 44.92 Mtce in 2050.

Table 8. Future energy intensity scenarios for building heating in northern areas of China $\left(\mathrm{kgce} /\left(\mathrm{m}^{2}-\mathrm{a}\right)\right)$.

\begin{tabular}{|c|c|c|c|c|c|c|c|}
\hline & \multirow{2}{*}{$\begin{array}{c}2018 \\
\text { Current }\end{array}$} & \multicolumn{3}{|c|}{2030} & \multicolumn{3}{|c|}{2050} \\
\hline & & Baseline & Medium & Strict & Baseline & Medium & Strict \\
\hline Heating of northern towns & 11.4 & $\begin{array}{c}7.3 \\
-35 \%\end{array}$ & $\begin{array}{c}6.6 \\
-42 \%\end{array}$ & $\begin{array}{c}6.0 \\
-47 \%\end{array}$ & $\begin{array}{c}5.3 \\
-54 \%\end{array}$ & $\begin{array}{c}4.3 \\
-62 \%\end{array}$ & $\begin{array}{c}3.9 \\
-66 \%\end{array}$ \\
\hline Heating of rural residences & 5.3 & $\begin{array}{c}6.3 \\
19 \%\end{array}$ & $\begin{array}{c}6.0 \\
13 \%\end{array}$ & $\begin{array}{l}5.8 \\
9 \%\end{array}$ & $\begin{array}{c}7.1 \\
34 \%\end{array}$ & $\begin{array}{c}6.6 \\
25 \%\end{array}$ & $\begin{array}{c}6.1 \\
15 \%\end{array}$ \\
\hline
\end{tabular}

The China Building Energy Conservation Association calculated the urban building energy consumption of each province (city) in China, in which the urban building energy consumption of 15 provinces (cities) in the northern region accounted for $41 \%$ of the total building energy consumption in the country [41]. Tsinghua University's research on national rural energy use showed that the rural residential energy consumption in 15 provinces (cities) in the northern region accounted for $62 \%$ of national rural energy consumption [15]. A comprehensive estimate shows that building energy consumption in northern China accounts for about $55 \%$ of the total building energy consumption in the country. In addition, heating energy has always been an important part of building energy consumption in the north. Figure 8 gives the heating energy consumption of residential buildings in northern regions under different scenarios. With low carbon requirements, building heating energy consumption in northern regions should be kept under at least a medium control scheme if we want to achieve peak carbon as early as possible.

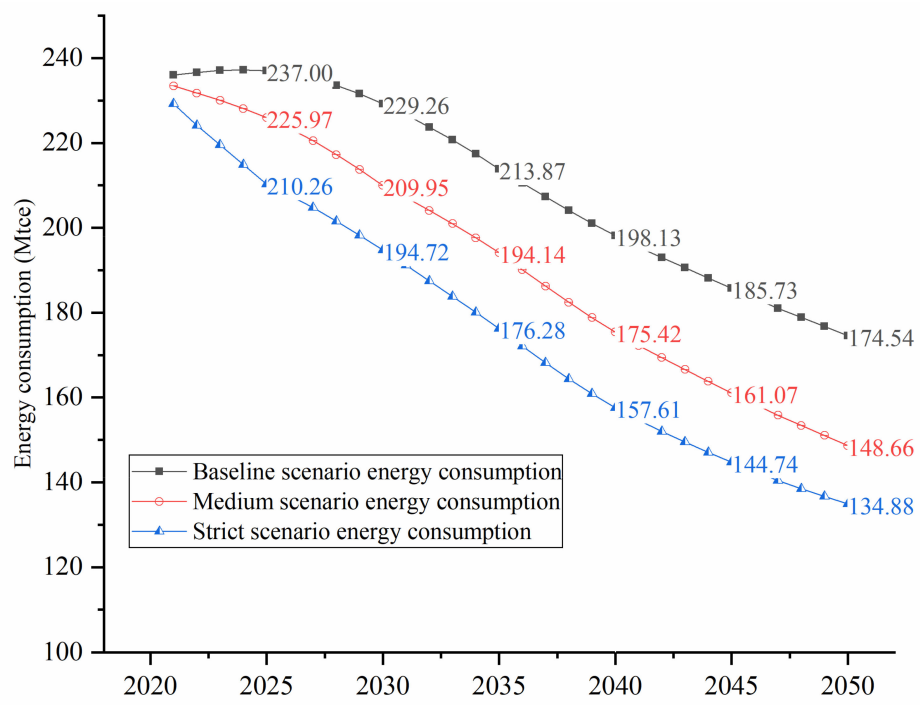

Figure 8. Total heating energy consumption in northern buildings under different scenarios. 


\subsection{Carbon Emissions from Building Heating in Northern Regions}

(1) Carbon emission factors. The most widely used carbon emission calculation method internationally is the carbon emission factor method proposed by IPCC, whose basic idea is to use the activity data of various emission sources and the product of emission factors as the carbon emission estimation value according to the carbon emission inventory list. The emission factors are more regional, and the carbon emission calculation standards for buildings in China are shown in Table 9 [42]. The electricity consumed for building energy consumption mainly comes from thermal power generation and renewable energy generation, and renewable energy generation is mainly clean energy such as wind, water, photovoltaic and nuclear energy, which can be regarded as zero carbon emission, so the electricity carbon emission factor can be obtained by dividing the carbon emissions from thermal power generation by the total national electricity generation. According to the data published by the State Grid, thermal power generation accounted for $70 \%$ of the total power generation in China in 2018, and the national electricity carbon emission factor was estimated to be $0.5 \mathrm{kgCO}_{2} / \mathrm{kWh}$ with reference to the electricity carbon emission factor of each region. According to the National Energy Board's forecast of China's medium- and long-term power generation capacity [43], the share of renewable energy generation will reach $40 \%$ in 2030 and about $50 \%$ in 2050, then the power carbon emission factor may drop to $0.52 \mathrm{kgCO}_{2} / \mathrm{kWh}$ in 2030 and about $0.38 \mathrm{kgCO}_{2} / \mathrm{kWh}$ in 2050 .

(2) Forecast of the energy structure. In terms of heating, for a long time to come, the main energy source for heating in northern towns will still be coal, and rural areas should continue to develop renewable energy sources such as photovoltaic, wind power and biomass to reduce the proportion of coal and other energy consumption in residential heating. In order to achieve the goal of carbon neutrality, coal should be gradually phased out from the heating energy system in the future and the proportion of renewable energy and clean energy should be increased. With reference to the proportion of energy use in the current energy balance sheet, the energy structure of urban and rural heating under the medium control scenario is projected as shown in Figure 9, and a new energy structure is projected after strengthening carbon emission control measures and increasing the utilization of new and clean energy sources such as rural biomass, nuclear energy and urban industrial waste heat under the medium control scenario.

(3) Prediction of carbon emissions from building heating under the medium control scenario. Figure 10 shows the future trend of building heating carbon emissions in the northern region of China under the medium control scenario. Under the medium control scenario, the carbon emissions from building heating in the northern region can be reduced to $450 \mathrm{MtCO}_{2}$ in 2050, and to $280 \mathrm{MtCO}_{2}$ with the adoption of more stringent energy-saving and emission reduction technologies.

Table 9. Carbon emission factors of various energy sources in China in 2018.

\begin{tabular}{|c|c|c|c|c|c|}
\hline Energy Type & Coal & Liquefied Petroleum Gas & Natural Gas & Biomass & Electricity \\
\hline Carbon emission factor & $94.44 \mathrm{kgCO}_{2} / \mathrm{GJ}$ & $61.81 \mathrm{kgCO}_{2} / \mathrm{GJ}$ & $55.54 \mathrm{kgCO}_{2} / \mathrm{GJ}$ & $76.5 \mathrm{kgCO}_{2} / \mathrm{GJ}$ & $0.58 \mathrm{kgCO}_{2} / \mathrm{kWh}$ \\
\hline
\end{tabular}

As can be seen from the Figure 10, building heating carbon emissions in the northern region are dominated by urban heating, accounting for about $75 \%$ of the total building heating carbon emissions in the north. In the medium scenario, urban heating carbon emissions reduce from $579 \mathrm{MtCO}_{2}$ in 2021 to $376 \mathrm{MtCO}_{2}$ in 2050, a reduction of $203 \mathrm{MtCO}_{2}$, accounting for $78 \%$ of the total emission reductions. In the medium control scenario to strengthen the reduction of carbon emissions, urban heating carbon emissions reduce from $572 \mathrm{MtCO}_{2}$ in 2021 to $209.8 \mathrm{MtCO}_{2}$ in 2050, a reduction of $363 \mathrm{MtCO}_{2}$. Therefore, urban building energy-saving and emission reduction should be the main goals of northern heating. 

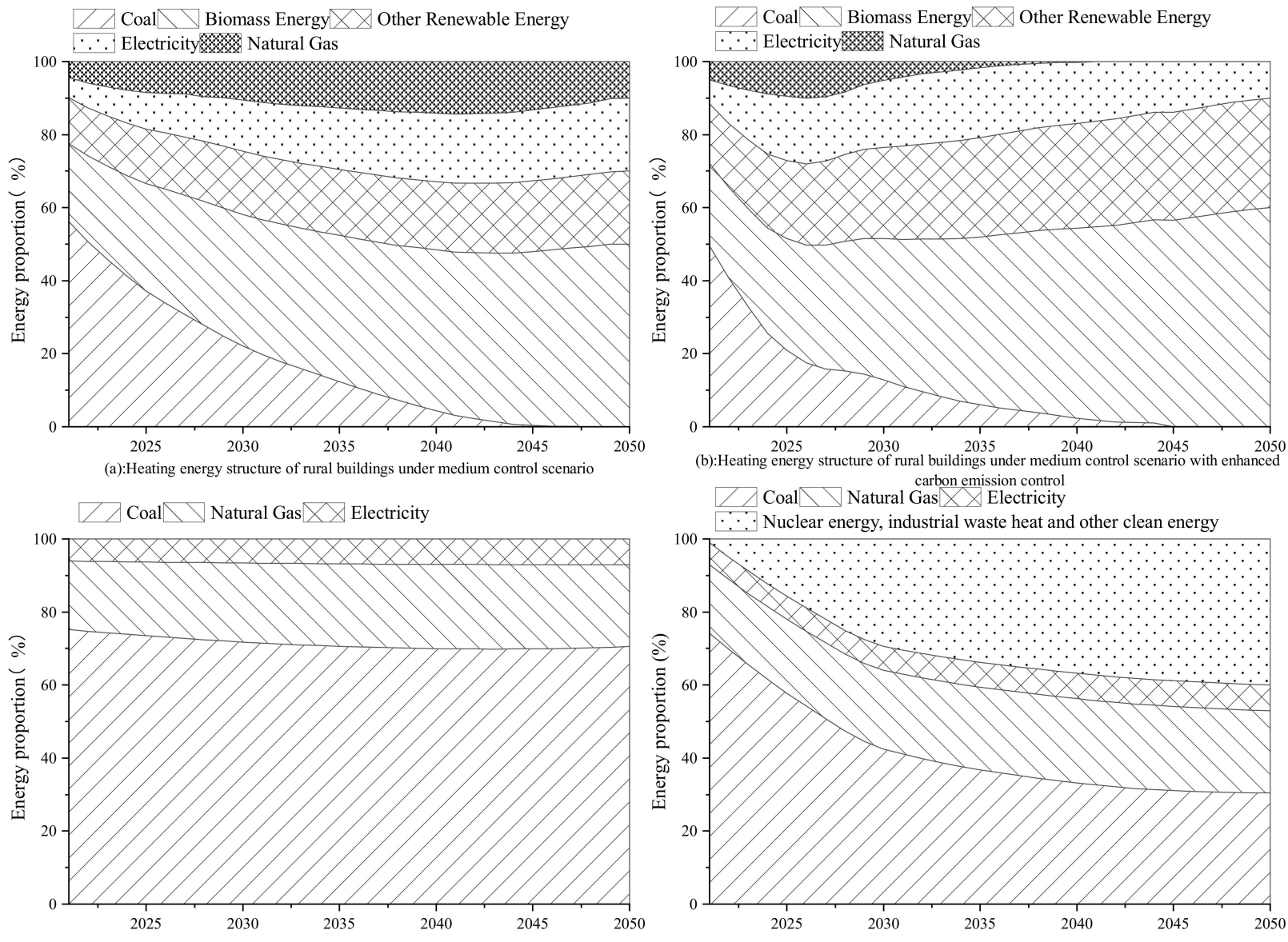

(c):Heating energy structure of urban buildings under medium control scenario

(d):Heating energy structure of urban buildings under medium control scenario with enhanced carbon emission control

Figure 9. Heating energy structure forecast for northern region.

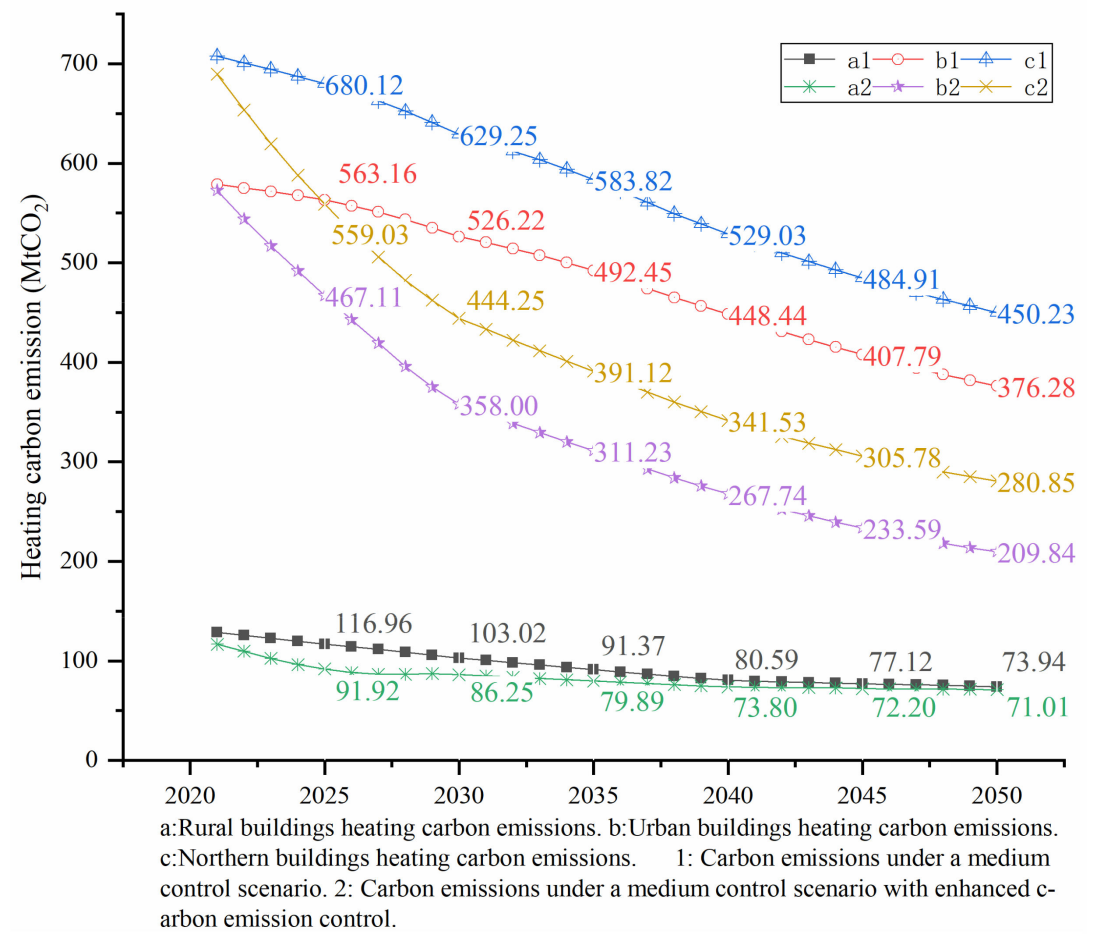

Figure 10. Future projection of heat carbon emissions from building heating in northern China. 


\section{Analysis of the Implementation Path of Heating Energy Saving in Northern Buildings}

Based on the existing northern clean heating policies, the energy intensity of urban heating in northern regions under the three scenarios set in this paper has a decreasing trend. In order to facilitate the analysis of energy savings from heating energy efficiency technologies, this part sets a non-energy-efficient heating energy scenario for heating energy consumption in northern towns, i.e., at the current heating energy intensity, the heating energy consumption in future heating of northern towns without any additional measures is compared with the heating energy consumption in a medium control scenario as shown in Figure 11. The implementation of $65 \%$ energy-saving standards for new civil buildings began in 2010, before which the stock of existing buildings in northern towns was about 10.5 billion $\mathrm{m}^{2}$. Although the total energy consumption of existing buildings and the proportion they account for is gradually decreasing due to their demolition or collapse year by year, due to their huge stock, without energy-saving renovation and operation and maintenance, the heating energy consumption in northern cities and towns will still reach 235 Mtce in 2050. Thus, the energy-saving potential of building heating energy-saving renovation and operation and maintenance is huge.

(1) Energy-saving renovation of envelope structure. The building envelope is the part that has the greatest impact on heating energy consumption. At present, the comprehensive heat transfer coefficient of the non-energy-saving building envelope in China is around 1.1 1.3 W/( $\left.\mathrm{m}^{2}-\mathrm{K}\right)$, while the comprehensive heat transfer coefficient of the building envelope that reaches the $65 \%$ energy-saving standard is about $0.8 \sim 1.0 \mathrm{~W} /\left(\mathrm{m}^{2}-\mathrm{K}\right)$. Currently, some northern regions have started to implement $75 \%$ energy efficiency standards, and the integrated heat transfer coefficient of new buildings has been reduced to $0.4 \sim 0.6 \mathrm{~W} /\left(\mathrm{m}^{2}-\mathrm{K}\right)[44,45]$. As of 2018 , about $60 \%$ of urban buildings in northern China had completed an energy-saving renovation, and assuming that all northern urban areas under the medium control scenario complete an energy-saving renovation of existing building envelopes in 2030 and the integrated heat transfer coefficient reaches $0.55-0.75 \mathrm{~W} /\left(\mathrm{m}^{2}-\mathrm{K}\right)$, heating energy consumption will drop to 193 Mtce in 2030. With the update of energy-saving standards, the heat transfer coefficient of the building envelope will be further reduced in the future, and, if the energy efficiency level of $75 \%$ is fully achieved in 2050, the heating energy consumption may reach $144 \mathrm{Mtce}$, which is 92 Mtce lower than the non-energy-saving scenario.

(2) Heat source restructuring. From the perspective of heating the heat source structure, heating in northern cities and towns in China is still mainly coal-fired, mainly through coal-fired cogeneration and coal-fired boilers for centralized heating, accounting for about $45 \%$ and $30 \%$ of heating methods, respectively. According to the requirements of clean heating planning, the scope of centralized heating should be expanded in the future, the proportion of gas heating should be increased, the use of loose coal should be reduced and heat sources such as electric heat pumps, industrial waste heat and renewable energy should be developed for heating. The future adjustment of the heat source structure in northern areas is shown in Figure 12; energy consumption for heating will reach 233 Mtce in 2030, decreasing to 224 Mtce in 2050, a reduction of 0.12 Mtce over the non-energy-efficient scenario.

(3) Heating source efficiency. At present, the heating capacity of cogeneration units has not been fully developed, and the waste heat of spent steam has not been fully utilized; most of the units have a heat-to-electricity ratio below 1.5. While the actual operation can be up to about three times, the heat-to-electricity ratio still needs to be improved. Compared with cogeneration, the boiler efficiency is obviously low. The thermal efficiency of large coal-fired boilers is around $70 \%$, and the efficiency of gas-fired boilers is above $85 \%$, so energy-saving renovation of boiler rooms can effectively improve the heating efficiency of boilers. With the development of science and technology, the efficiency of various heat pumps for heating is also improving. The ground source heat pump COP is usually between 3 and 5 , while the heat pump 
efficiency can be increased to about 8 through the inverter centrifugal technology. Assuming that the heating coal consumption of various heating methods can reach the level of Table 10 in the future through new energy-saving technologies for heating, the heating energy consumption can be reduced to 213 Mtce in 2050, and the energy saving is about 0.23 billion tce compared with the non-energy-saving scenario.

(4) Energy-saving renovation of transmission and distribution pipeline network. At present, the heat loss of China's urban centralized heating pipe network is more serious, and GB/T 51161 limits the heat loss rate of the pipe network and the index of transmission and distribution consumption, as shown in Table 11. If the heat loss rate of the pipe network in 2050 under the medium control scenario can be controlled within the district heating constraint value, the pipe network efficiency will reach $95 \%$ and the transmission and distribution consumption will drop from 3 to $2 \mathrm{kWh} /\left(\mathrm{m}^{2}-\mathrm{a}\right)$, then heating energy consumption can reach 219 Mtce in 2030 and be controlled to 192 Mtce in 2050, which is a 44 Mtce reduction compared to non-energy-saving scenarios.

(5) Heat metering. Heat metering buildings set temperature control valves indoors. When the indoor temperature is higher than the temperature set by the temperature control valve, the heating system temperature control valve will reduce the opening or close the valve to provide less heat to the room and vice versa to increase the heat supply. However, since its introduction, the heat metering policy has not been popularized due to uneven heat supply, lax monitoring and unreasonable charges. However, heat metering has an important role for heating energy saving. Actual cases show that the annual heat consumption of a centrally heated building has decreased from 87 to $63 \mathrm{kWh} /\left(\mathrm{m}^{2}-\mathrm{a}\right)$ since the implementation of heat metering retrofit, which is a $28 \%$ reduction [46]. This article assumes that under the medium scenario full heat metering charges will be reached in 2050, the annual heat consumption of urban heating buildings in northern regions will be reduced from 74 to $53 \mathrm{kWh} /\left(\mathrm{m}^{2}-\mathrm{a}\right)$, and the heating energy consumption will be about 170 Mtce. Compared with the non-energy-saving scenario, the energy saving will be about 65 Mtce.

Table 10. Future coal consumption for heating from various heating sources.

\begin{tabular}{cccc}
\hline & $\mathbf{2 0 1 8}$ & $\mathbf{2 0 3 0}$ & $\mathbf{2 0 5 0}$ \\
\hline Coal-fired cogeneration & 21 & 20 & 19 \\
Gas cogeneration & 23 & 21 & 20 \\
Coal-fired boiler & 39 & 37 & 35 \\
Gas boiler & 35 & 33 & 32 \\
Centralized heat pump & 28 & 26 & 25 \\
Gas wall-mounted furnace & 32 & 31 & 30 \\
Electricity & 84 & 79 & 75 \\
\hline
\end{tabular}

Table 11. Heat loss of pipe network and limit of transmission and distribution consumption index.

\begin{tabular}{|c|c|c|c|}
\hline & & Constraint Value & Guide Value \\
\hline \multirow{3}{*}{$\begin{array}{c}\text { Index of heat loss rate of pipe } \\
\text { network }(\%)\end{array}$} & District central heating & 5.0 & 3.0 \\
\hline & Centralized heating in community & 2.0 & 1.0 \\
\hline & Heating for 4 months & 1.7 & 1.0 \\
\hline \multirow{3}{*}{$\begin{array}{l}\text { Water pump power consumption } \\
\text { index of pipe network }\left(\mathrm{kWh} /\left(\mathrm{m}^{2}-\mathrm{a}\right)\right)\end{array}$} & Heating for 5 months & 2.1 & 1.3 \\
\hline & Heating for 6 months & 2.5 & 1.5 \\
\hline & Heating for 7 months & 2.9 & 1.8 \\
\hline
\end{tabular}

The heating energy consumption and energy savings in 2050 after adopting the above energy-saving technologies, compared to the non-energy-saving scenario, are shown in Table 12. However, different energy-saving technologies are interrelated; for example, the improvement of the maintenance structure will at the same time enhance the effect of heat metering and the change in the heat source structure will also affect the heat source efficiency. Therefore, the energy consumption and energy saving in the table are the results 
of a single action relative to the non-energy-saving scenarios, and the baseline, medium and strict control scenarios in the previous section are a comprehensive consideration of various technology development policy changes, which are reflected in the energy consumption intensity.

$\square / 7 \triangle$ Energy consumption in non-energy-saving scenario $\square$ Medium control scenario energy consumption $-\$-$ Proportion of heating in non-energy-saving scenario $-\mathrm{O}-$ Proportion of heating in medium control scenario

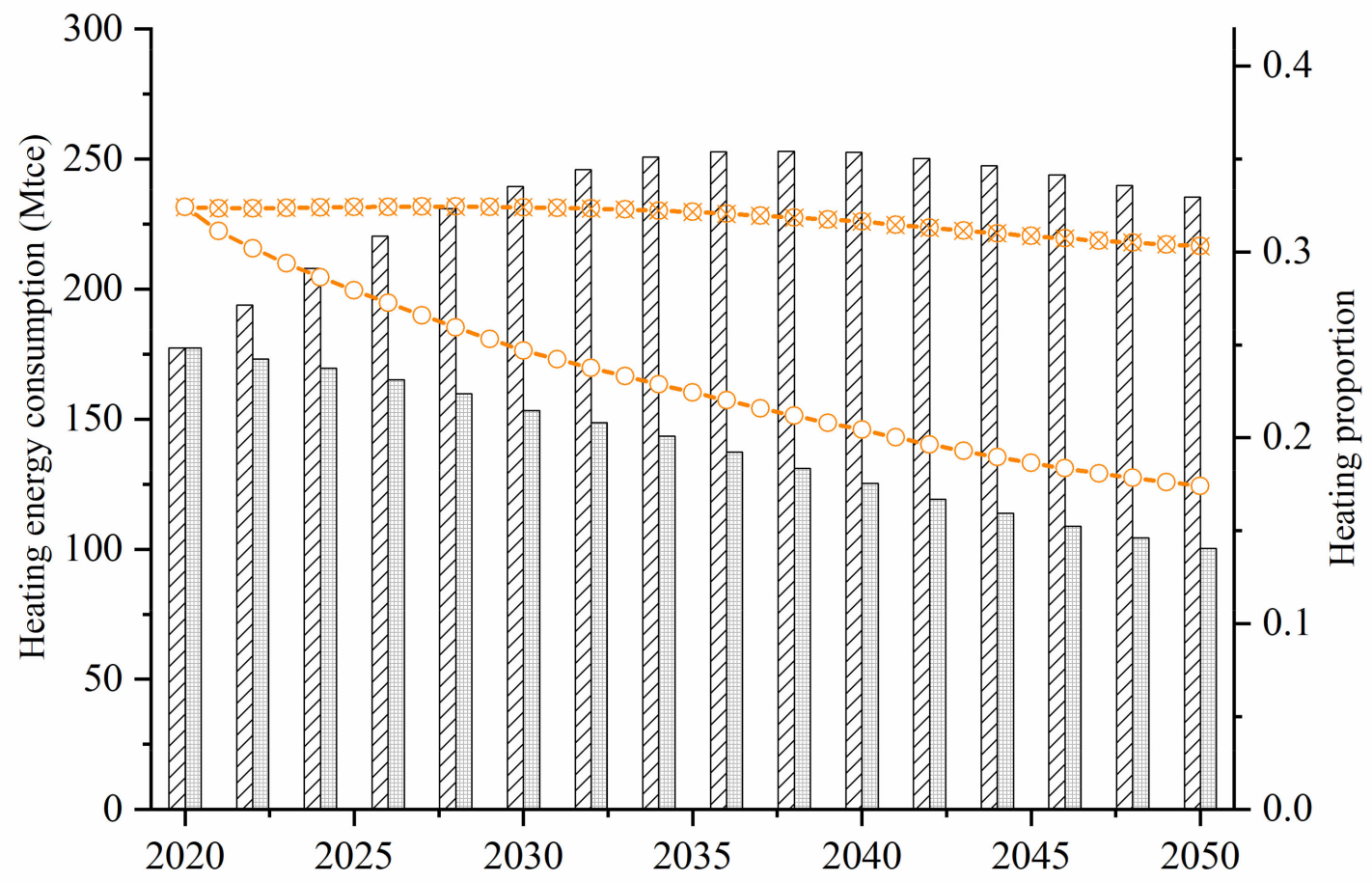

Figure 11. Comparison of heating energy consumption in the non-energy-saving scenario and the medium control scenario.

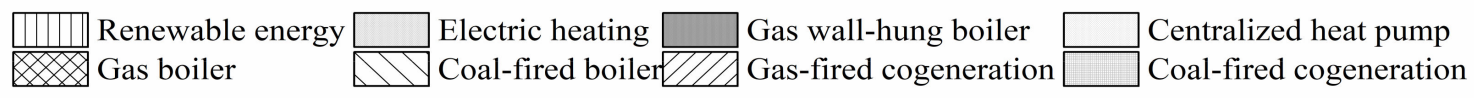

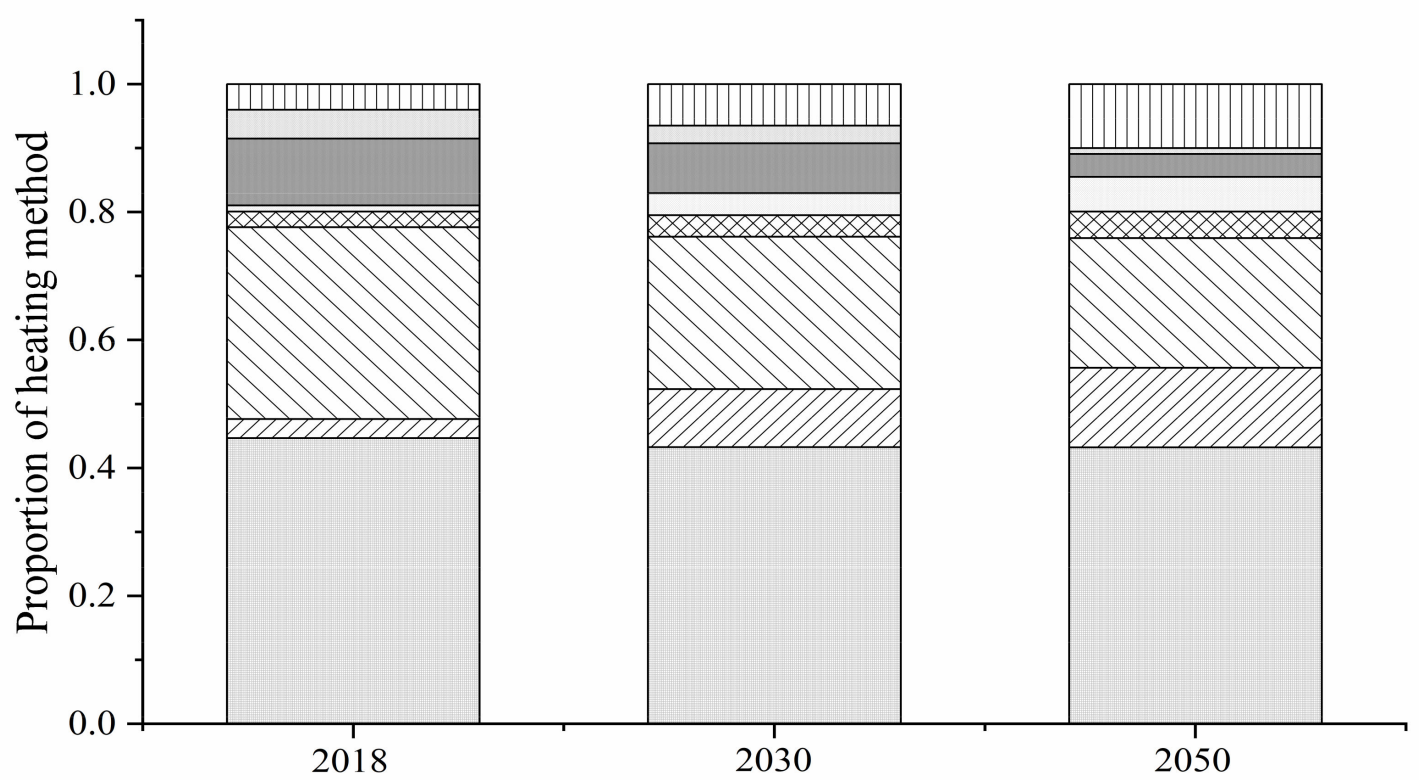

Figure 12. Comparison of heating heat source structures. 
Table 12. Heating energy consumption and energy savings with energy efficiency measures compared to non-energy-efficient scenario (Mtce).

\begin{tabular}{ccc}
\hline Energy-Saving Heating Technology & Energy Consumption in 2050 & Energy Saving \\
\hline Renovation of envelope structure (75\% energy saving) & 144 & 92 \\
Heat source restructuring & 224 & 12 \\
Heating source efficiency improvement & 213 & 23 \\
Renovation of pipeline & 192 & 44 \\
Heat metering & 170 & 65 \\
\hline
\end{tabular}

Figure 13 compares the energy savings of various energy-efficient technologies for heating in northern towns and cities and clearly shows the difference in energy consumption between the non-energy-efficient scenario and the medium control scenario. It can be seen that building envelope renovation contributes the most to heating energy saving, and building energy saving should focus on this. Heat source structure adjustment has the least effect on heating energy consumption, but, from the perspective of carbon emissions, improving the heat source structure can effectively reduce carbon emissions and promote carbon peaking. The analysis of energy savings of each type of technology in the figure is the result of its single action. In order to achieve the target of urban heating energy consumption under the medium control scenario, all types of energy-saving technologies should also be used in combination with China's national conditions.

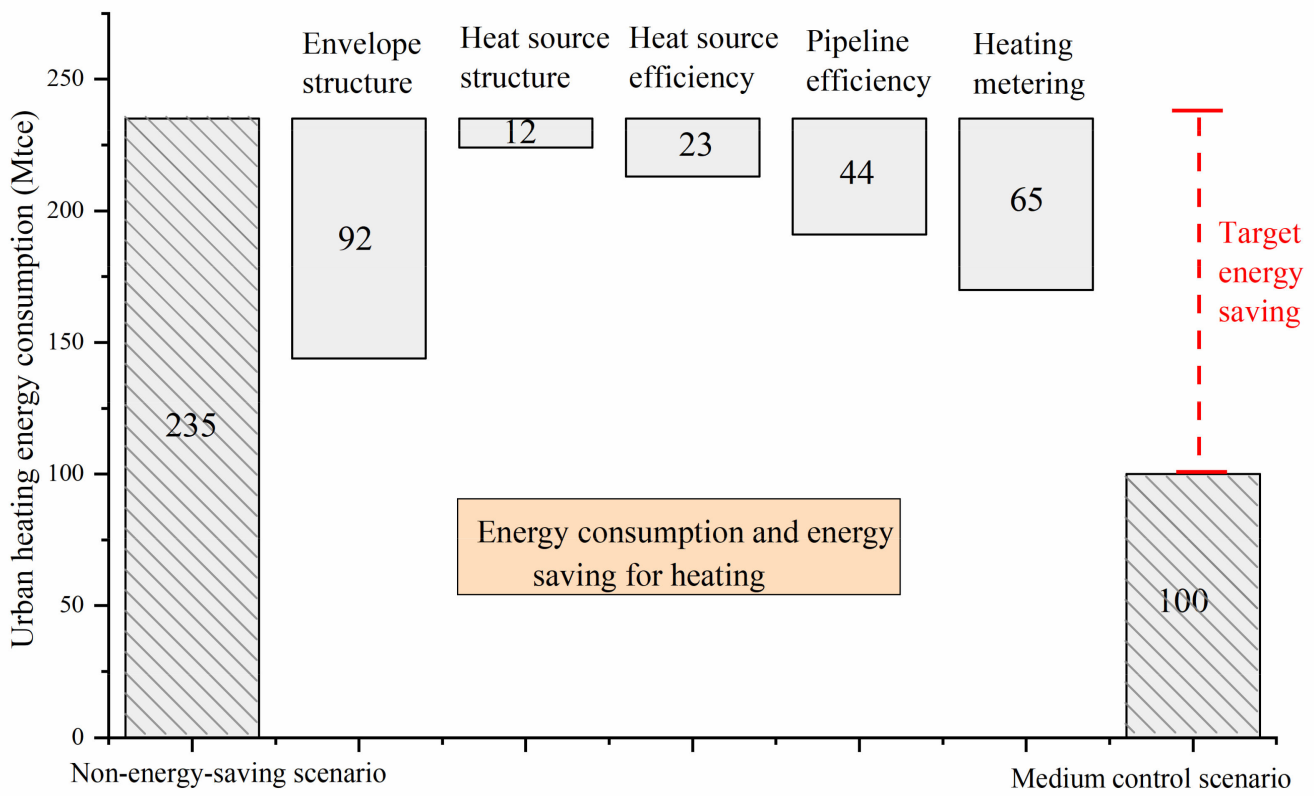

Figure 13. Comparison of energy savings of heating energy-saving technologies in northern towns.

According to the above analysis of various building energy efficiency technologies, combined with China's building energy efficiency policy measures, in order to achieve the energy consumption target of the medium control scenario, the development path of civil building heating energy efficiency in northern China is shown in Figure 14.

For the vast rural areas in northern China, the different climatic conditions, geography and economic development should perhaps prompt us to shift our focus from simply reducing the energy intensity of rural heating as a way to reduce carbon emissions to reducing the energy intensity of heating and developing the use of clean energy for heating to reduce carbon emissions. Biomass and solar energy are widely distributed and accessible in rural areas with very different natural and energy conditions. Improving the use of biomass and thus reducing carbon emissions has already been described. Solar energy for rural heating can be divided into active and passive types, according to whether 
mechanical power is required to drive the elements [47]. However, due to the low energy flow density, instability and mismatch between the heating characteristics of solar energy and the building load, solar energy is often used in combination with multiple energy sources for complementary heating to enhance the contribution of solar energy in renewable energy and system energy efficiency [48].

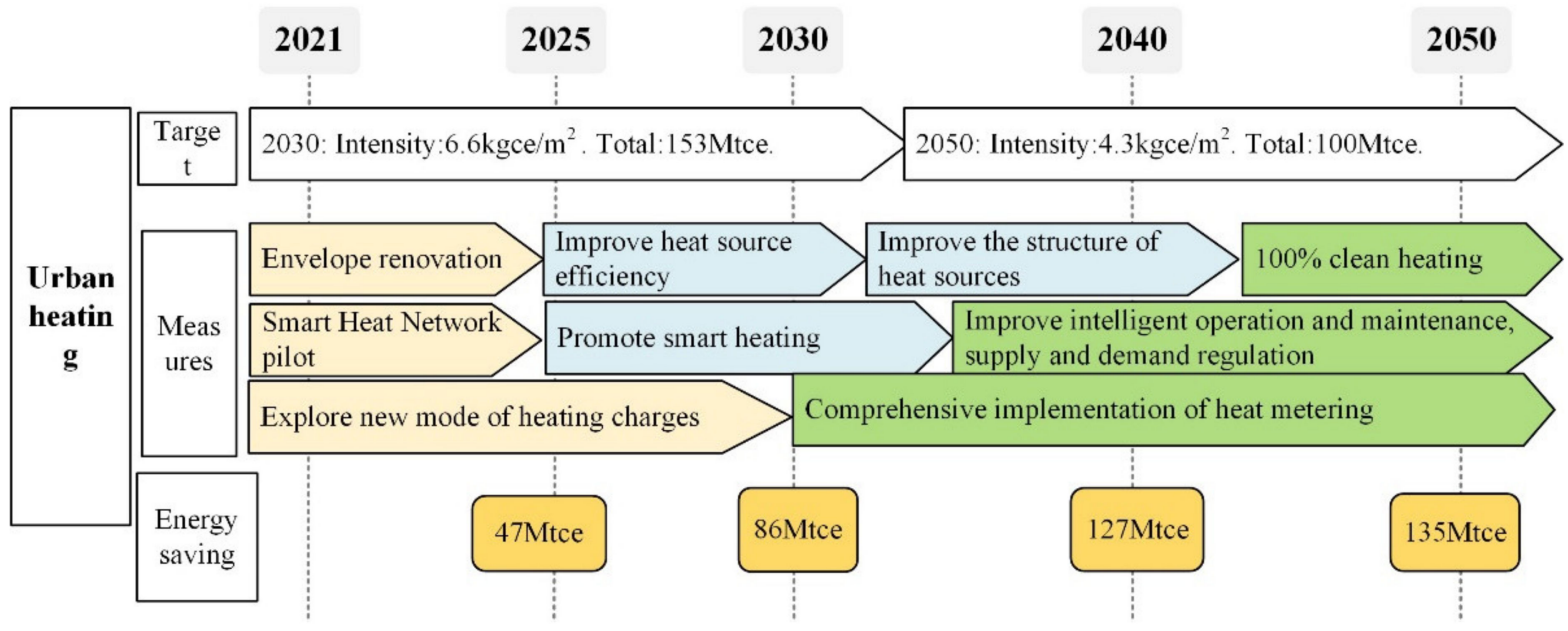

Figure 14. Development path of civil building energy efficiency in northern towns.

An example is the common coupled solar-air source heat pump system. Chengyang Jiang [49] et al. proposed a ribbed collector for DXSASHPWH, where the collector can absorb heat in the air and also in the solar radiation, and the average COP of the system can reach 6, which is much higher than the conventional-type system. Shan Ming [10] et al. selected a demonstration household located in the rural Pinggu District, Beijing; the heating system was a solar hot water collector system plus $4 \mathrm{~kW}$ flow inverter low-temperature air source heat pump hot water machine, the end unit used geothermal radiant heating, with the whole heating season solar hot water circulation pump power consumption of about $151 \mathrm{kWh}$, a low-temperature air source heat pump hot water system power consumption of $6104 \mathrm{kWh}$ and carbon emissions of $2790 \mathrm{~kg}$, much lower than the carbon emissions of traditional heating methods [50]. Meysam, Huide Fu [51,52] et al. designed a PV/T system based on heat pipes by combining cylindrical heat pipes with photovoltaic modules and combined it with a heat pump to design a solar heat pump system based on cylindrical heat pipes, where the average COP of the heat pump system could reach 4.87 and the photovoltaic efficiency was above $11 \%$. The green electricity generated by the PV system can also be used for heat pump heating, thus reducing the carbon emissions from heating. This is promising in provinces such as Tibet, Inner Mongolia and Qinghai, where solar energy resources are abundant. In addition, a solar-geothermal source heat pump coupling system, solar-water source heat pump coupling system, etc. can achieve the same energysaving and emission reduction effect, which needs to be determined according to the actual local climate, geography and economic situation. Due to the instability of solar energy and the various conditions in different regions, such systems are more complex, and the specific form is difficult to determine, so no further detailed calculations will be made, but rather they will be grouped with other green energy sources under the category of rural renewable energy.

\section{Conclusions}

By analyzing the historical data of civil buildings and relevant energy consumption models, this paper classifies and predicts the civil building area in the north by considering various factors, calculates and predicts the building energy consumption of different types of buildings, and establishes a macro-level calculation model of heating energy consumption of civil buildings in the north to obtain detailed data of heating energy 
consumption of buildings in the north of China. By analyzing the year-to-year changes in energy consumption and future development trends, the control target of building heating energy consumption in northern China under the carbon emission constraint is determined. Through the analysis of building energy-saving technologies, the key points of heating energy saving and emission reduction are clarified, providing a relevant basis for the formulation of heating energy consumption and carbon emission control policies in northern China. The main conclusions are as follows:

(1) Population, urbanization rate and the economic development level are the main influencing factors of building area. As urbanization accelerates, urban residential and public building area will increase, reaching a peak around 2040, while rural residential building area will continue to decline. Among public buildings, medical, education, office and commercial buildings account for $73 \%$ of the total public buildings, and area control should focus on these buildings.

(2) Under the total energy and carbon emission constraints, total energy consumption in the northern region should be controlled at least below the medium control scenario in the future. Under this target, China's total population will peak at 1.412 billion in 2027; the urbanization rate will enter a plateau after reaching $75 \%$ in 2040 ; the residential building area in the northern region will peak at 35.2 billion $\mathrm{m}^{2}$ in 2035 ; the heating energy consumption in northern towns will decrease, falling to $6.6 \mathrm{kgce} /\left(\mathrm{m}^{2}-\mathrm{a}\right)$ in 2030 and to $4.3 \mathrm{kgce} /\left(\mathrm{m}^{2}-\mathrm{a}\right)$ in 2050; and rural residential heating energy consumption will increase with economic development, growing to $6.0 \mathrm{kgce} /\left(\mathrm{m}^{2}-\mathrm{a}\right)$ in 2030 and possibly to $6.6 \mathrm{kgce} /\left(\mathrm{m}^{2}-\mathrm{a}\right)$ in 2050 .

(3) To achieve the medium control target, it is necessary to make comprehensive use of various energy-saving technologies. In rural areas, attention should be paid to the effective use of biomass energy, local use of solar, geothermal and other green renewable energy. In terms of urban heating energy-saving technology, the transformation of the building envelope contributes the most to heating energy saving, reaching 92 Mtce. Building energy saving should focus on this, supplemented by technical means such as pipe network and heat source transformation to control heating energy consumption. At the same time, the development and utilization of clean heating technology should be strengthened to replace coal consumption in urban heating.

Author Contributions: Conceptualization, Y.Z. and W.Z.; methodology, Y.Z. and W.Z.; formal analysis, W.Y. and J.L.; investigation, W.Y. and J.L.; data curation, K.W. and K.L.; writing-original draft preparation, W.Y. and J.L.; writing-review and editing, Y.Z. and W.Z.; visualization, K.W. and K.L. All authors have read and agreed to the published version of the manuscript.

Funding: This research was funded by the National Natural Science Foundation of China, grant number 51908287; the China National Key R\&D Program, grant number 2018YFC0704400; and the National Natural Science Foundation of Jiangsu Province, grant number BK20180484.

Institutional Review Board Statement: Not applicable.

Informed Consent Statement: Not applicable.

Data Availability Statement: The data presented in this study are available on request from the corresponding author. The data are not publicly available due to privacy.

Conflicts of Interest: The authors declare no conflict of interest.

\section{References}

1. Andrew, N. The IPCC's Report on Global Warming of $1.5^{\circ} \mathrm{C}$ Spells out the Urgency of Action; International Institute for Environment and Development: London, UK, 2018.

2. Jinping, X. Address to the general debate of the 75th session of the United Nations General Assembly. Gaz. StateCouncil People Repub. China 2020, 28, 5-7.

3. Beibei, Q. Research on China's Building Energy Consumption Statistical Method. Master's Thesis, Chongqing University, Chongqing, China, 2014. 
4. EIA. Residential Energy Consumption Survey Household Questionnaire. 2009. Available online: https://www.iea.org/reports / armenia-energy-profile (accessed on 5 October 2021).

5. U.S. DOE Energy Information Administration. Model Documentation Report: Residential Sector Demand Module of the National Energy Modeling System; DOE/EIA-M067(97); U.S. DOE Energy Information Administration: Washington, DC, USA, 2005.

6. Clark, V.; Heaps, C. LEAP: Long-range Energy Alternatives Planning System. Available online: http://www.energycommunity.org (accessed on 23 November 2021).

7. Liu, J.; Xiang, Q.; Wang, K.; Zou, J.; Kong, Y. Mid- to long-term low carbon development pathways of China's building sector. Resour. Sci. 2019, 41, 509-520.

8. Xinyi, L. A Study About Residential Building Stock Energy Modelling. Ph.D. Thesis, Chongqing University, Chongqing, China, 2018.

9. Xueling, L.; Weijuan, F.; Yuanming, W. Simulation and prediction of building energy consumption based on climate and population change. In Proceedings of the 2021 Seminar on Construction and Efficient Operation of Heat Supply Projects, Chengdu, China, 21 April 2021.

10. Despotovic, M.; Koch, D.; Leiber, S.; Doeller, M.; Sakeena, M.; Zeppelzauer, M. Prediction and analysis of heating energy demand for detached houses by computer vision. Energy Build. 2019, 193, 29-35. [CrossRef]

11. Xiu, Y. Study of China's Building Energy Efficiency Based on Energy Data. Ph.D. Thesis, Tsinghua University, Beijing, China, 2009.

12. National Bureau of Statistics of People's Republic of China. China Statistical Yearbook-2013; China Statistics Press: Beijing, China, 2013

13. Menghui, W. Significant achievements have been made in the development of housing and urban-rural construction during the "13th Five-Year Plan" period. China Eng. Consult. 2020, 12, 16-18.

14. China Association of Building Energy Efficiency-Energy Consumption Statistics Professional Committee. China Energy Consumption Research Report 2020; China Association of Building Energy Efficiency: Beijing, China, 2020.

15. Research Center for Building Energy Efficiency, Tsinghua University. 2020 Annual Report on China Building Energy Efficiency; China Construction Industry Press: Beijing, China, 2020; pp. 2-5.

16. National Bureau of Statistics. China Statistical Yearbook. Available online: http://www.stats.gov.cn/tjsj/ndsj/ (accessed on 5 October 2021).

17. China Survey and Data Center, National People's University of China. China General Social Survey (CGSS). Available online: http:/ / cgss.ruc.edu.cn/ (accessed on 5 October 2021).

18. Sun, W.K. Changes in the number of households and housing demand in China. Soc. Sci. J. 2020, 6, 160-166.

19. National Health and Family Planning Commission. China Family Development Report 2015; China Population Press: Beijing, China, 2015.

20. State Council of the People's Republic of China. Notice on the Issuance of the National Land Planning Outline (2016-2030); State Council of the People's Republic of China: Beijing, China, 2017; pp. 35-64.

21. Ministry of Housing and Urban-Rural Development of People's Republic of China. China Urban and Rural Construction Statistical Yearbook; China Plan Press: Beijing, China, 2018.

22. Institute of Standardization, Ministry of Housing and Urban-Rural Development. Energy Consumption Control Strategy of Civil Buildings; China Construction Industry Press: Beijing, China, 2016.

23. Tongdan, G.; Wenjie, Z.; Jinhan, L.; Changqing, L.; Kai, M. Forecast and analysis of the total amount of civil buildings in China in the future based on population driven. Sustainability 2021, 13, 14051. [CrossRef]

24. Wang, Y.; Wei, Q.; Xue, Z.; Jiang, Y. Large-scale public building energy conservation consultation (3)-Investigation and analysis investigation and analysis of energy consumption in large public buildings. Constr. Sci. Technol. 2007, 2, 17-19.

25. Ministry of Housing and Urban-Rural Development of People's Republic of China. China Urban Construction Statistical Yearbook; China Construction Industry Press: Beijing, China, 2006.

26. Wang, Y.; Qiao, J. Trends and social determinants of adolescent marriage and fertility in China. Lancet Glob. Health 2020, 8 , e873-e874. [CrossRef]

27. Xianling, Z.; Zhenwu, Z.; Tao, T. Trends and patterns of negative population growth in China. Popul. Res. 2020, 44, 3-20.

28. National New Urbanization Plan (2014-2020). Rural Work Newslett. 2014, 6, 32-48.

29. Tianjin Development and Reform Commission: "Thirteenth Five-Year Plan" for Tianjin Heating Development. Available online: http://fzgg.tj.gov.cn/zwgk_47325/zcfg_47338/zcwjx/fgwj/202012/t20201219_5069573.html (accessed on 26 November 2021).

30. Department of Housing and Urban-Rural Development. Hebei: “Thirteenth Five-Year Plan" for Urban Heating in Hebei Province. Available online: http:/ /zfcxjst.hebei.gov.cn/cszsdw/hbsrqrlglzx/tfwj/201705/t20170526_228033.html (accessed on 20 November 2021).

31. Ministry of Housing and Urban-Rural Development of People's Republic of China. Standard for Energy Consumption of Building; GBT 51161-2016; China Construction Industry Press: Beijing, China, 2016.

32. National Development and Reform Commission of the People's Republic of China: Clean Heating Plan in Winter in Northern area (2017-2021). Available online: http:/ / www.gov.cn/xinwen/2017-12/20/content_5248855.htm (accessed on 23 November 2021).

33. Research Center for Building Energy Efficiency, Tsinghua University. 2019 Annual Report on China Building Energy Efficiency; China Construction Industry Press: Beijing, China, 2019. 
34. Li, Y.; Zhang, X.; Zhou, T. A heat transfer calculation method and primary verification for high-tempture fluid transmission and distribution network from EAST. Fusion Engineering and Design 2020, 151, 111403. [CrossRef]

35. Xu, Q.; Wang, K.; Zou, Z.; Zhong, L.; Akkurt, N.; Feng, J.; Xiong, Y.; Han, J.; Wang, J.; Du, Y. A new type of two-supply, one-return, triple pipe-structured heat loss model based on a low temperature district heating system. Energy 2021, 218, 119569. [CrossRef]

36. Beijing Urban Construction Science Technology Promoting Association. Technical Code for Retrofitting Heating System on Energy Efficiency; GB/T 50893-2013; China Construction Industry Press: Beijing, China, 2014.

37. Ministry of Housing and Urban-Rural Development of People's Republic of China. Design Standard for Energy Efficiency of Residential Buildings in Severe Cold and Cold Zones; JGJ 26-2010; China Construction Industry Press: Beijing, China, 2010.

38. Ministry of Housing and Urban-Rural Development of People's Republic of China. Design Standard for Energy Efficiency of Residential Buildings in Severe Cold and Cold Zones; JGJ 26-2018; China Construction Industry Press: Beijing, China, 2018.

39. Zhao, N.; Li, B.; Li, H.; Li, G.; Wu, R.; Hong, Q.; Mperejekumana, P.; Liu, S.; Zhou, Y.; Ahmad, R.; et al. The potential co-benefits for health, economy and climate by substituting raw coal with waste cooking oil as a winter heating fuel in rural households of Northern China. Environ. Res. 2021, 194, 110683. [CrossRef] [PubMed]

40. Research Center for Building Energy Efficiency, Tsinghua University. 2016 Annual Report on China Building Energy Efficiency; China Construction Industry Press: Beijing, China, 2016.

41. China Association of Building Energy Efficiency-Energy Consumption Statistics Professional Committee: China Building Energy Consumption Study Report 2018. Available online: https://www.cabee.org/site/content/22960.html (accessed on 22 November 2021).

42. Ministry of Housing and Urban-Rural Development of People's Republic of China. Standard for Building Carbon Emission Calculation; GBT 51366-2019; China Construction Industry Press: Beijing, China, 2019.

43. National Energy Administration: China's Mid- to Long-Term Power Generation Capacity and Power Demand Development Forecast. Available online: http://www.nea.gov.cn/2013-02/20/c_132180424_2.htm (accessed on 22 November 2021).

44. Department of Housing and Urban-Rural Development. Hebei. Design Standard for Energy Efficiency of Residential Buildings in Hebei Province (Energy Saving 75\%); DB13(J)185-2015; China Construction Industry Press: Hebei, China, 2015.

45. Department of Housing and Urban-Rural Development. Jilin. Design Standard for Energy Efficiency of Residential Buildings in Jilin Province (Energy Saving 75\%); DB22/T 5034-2019; China Construction Industry Press: Jilin, China, 2019.

46. Chunhua, S. Study on Heat Using Mode and Heat Consumption Characteristics in Buildings Adopting Heat Metering Systems. Ph.D. Thesis, Chongqing University, Chongqing, China, 2012.

47. Zhang, X.; Congcong, Z.; Wenjie, X.; Haidong, Z. Utilization of solar energy in green buildings. Sci. Technol. Inf. 2019, 4, 37-38.

48. Shanshan, X.; Deying, L. Development and application of solar-multi-energy complementary heating technology. In Proceedings of the 2021 Seminar on Construction and Efficient Operation of Heat Supply Projects, Chengdu, China, 21 April 2021.

49. Chengyang, J.; Yanjun, D. Direct expansion solar assisted heat pump using novel fin- tube collector/evaporator. CIESC J. 2016, 67, 318-325.

50. Ming, S.; Yanqing, L.; Rongjiang, M.; Mengsi, D.; Xingli, D.; Xudong, Y.; Yongjie, Z.; Jiandong, Y. Comparison of economic and emission performances of different technologies from coal to clean energy in northern rural China. Environ. Sustain. Dev. 2020, 45, $43-49$.

51. Long, H.; Tai, T.T.; Chow, J.J. Building-integrated heat pipe photovoltaic/thermal system for use in Hong Kong. Sol. Energy 2017, 155, 1084-1091. [CrossRef]

52. Dehui, F. Numerical and Experimental Study on a Heat Pipe Photovoltaic/Thermal System. Ph.D. Thesis, University of Science and Technology of China, Hefei, China, 2012. 